\title{
Identification of antibacterial phytochemicals in Terminalia arjuna (Roxb.) Wight \& Arn. and Andrographis paniculata (Burm.f.) Nees for the treatment of multidrug resistant (MDR) bacterial pathogens: An in silico analysis
}

\author{
Vidya Devanathadesikan Seshadri
}

Department of Pharmacology and Toxicology, College of Pharmacy, Prince Sattam bin Abdulaziz University, Al-Kharj, 11942, Saudi Arabia

\section{Article Info}

Article history

Received 7 March 2021

Revised 27 April 2021

Accepted 28 April 2021

Published online 30 June 2021

Keywords

Multi drug resistance

Phytochemicals

Terminalia arjuna

Andrographis paniculata

Molecular docking

In silico ADMET analysis

\begin{abstract}
The wide spread of multidrug resistant (MDR) bacteria is one of the global challenges of the $21^{\text {st }}$ Century. The indiscriminate use, overuse and the misuse of antibiotics are the major reasons for the high rates of microbial resistance. Medicinal plants have been a valuable source of natural products for maintaining human health, and the extensive investigations for compounds with potentials have been made in the past decades with a number of discoveries. The present study focuses on identification of novel antibacterial phytochemical compounds present Terminalia arjuna (Roxb.) Wight \& Arn. and Andrographis paniculata (Burm.f.) Nees by in silico analysis. The compounds were retrieved from KNApSAck database Tyrosyl-tRNA synthetase and DNA gyrase subunit b were used as target proteins. Preliminarily, the compounds were subjected to druglikness analysis. Molecular docking and proteinligand interactions were performed to identify the compounds with higher binding energies $(>-7 \mathrm{kcal} /$ mol). The selected compounds were examined for in silico ADMET analysis. Nearly, 20 phytochemical compounds were identified with higher binding energies and significant ADMET properties. These compounds can be used for development of novel antibacterial drug to overcome the multidrug resistance.
\end{abstract}

\section{Introduction}

The wide spread of multidrug resistant (MDR) bacteria is one of the global challenges of the $21^{\text {st }}$ Century. In general, a pathogen is called multidrug resistant (MDR) when it shows resistance against three or more antibiotics. The irony is that, even though the past three decades in particular have witnessed for the development of a number of new antibiotics, the number of bacterial species showing resistance to these agents were also increasing. In general, bacteria have the genetic ability to transmit and acquire resistance to drugs, which are utilized as therapeutic agents (Aslam et al., 2018; Elbossaty, 2017).

The efficiency of the many of the antibiotics in use is being limited due to the emergence of MDR strains. Moreover, the indiscriminate worldwide overuse and misuse of antibiotics are the other reasons for the high rates of microbial resistance. The impact of antibiotic resistance on the society is very serious as revealed in a study that, an average of 33,000 mortalities arise just from the MDRs and that the magnitude of these infections is comparable to the combined results of the major diseases, tuberculosis, influenza and HIV/AIDS. Thus, the increasing number of MDRs and the re-emergence of once 'eradicated' pathogens, all resistant to antibiotics in use-pose a real threat that could lead the world back to the pre-antibiotic era (Reygaert, 2018; Nikaido, 2009).

Corresponding author: Dr. Vidya Devanathadesikan Seshadri Assistant Professor, Department of Pharmacology and Toxicology, College of Pharmacy, Prince Sattam bin Abdulaziz University, Al-Kharj, 11942, Saudi Arabia

E-mail: vidya205@gmail.com

Tel.: +96-6530370974

Copyright (c) 2021 Ukaaz Publications. All rights reserved.

Email: ukaaz@yahoo.com; Website: www.ukaazpublications.com
For a long period of time, plants have been a valuable source of natural products for maintaining human health, and detailed studies were conducted with a number of potential findings on their therapeutic potentials in the past few decades. The use of plant compounds for pharmaceutical purposes has gradually increased. The World Health Organization have already recognized the medicinal plants as the best available natural source for a variety of potential bioactive compounds that may lead to potential drug. About $80 \%$ of individuals from developed countries use traditional medicine, which has compounds derived from medicinal plants. Therefore, such plants should be investigated to better understand their properties, safety and efficiency (Levy and Bonnie, 2004; Paritala et al., 2015).

As mentioned elsewhere, there are a number of purified phytochemicals and herbal extracts and composites with significant antibacterial properties and their use as therapeutic agents is highly recommended. In many plants, the compounds synthesized as a result of their secondary metabolism are contributing the antimicrobial activities. These products are known by their active substances (Borges et al., 2016). For example, T. arjuna and A. paniculata is extensively used in Ayurveda, Unani and Siddha medicine as home remedy for various diseases in Indian traditional system as well as in tribal medicine applications. Integration of bioinformatics tools with metabolomics, proteomics and comparative genomics is of great value for the identification of drug targets in a pathogen; moreover, this strategy can reduce the number of in vitro trials, rendering the drug discovery process more economical and less laborious (Abu Bin Nyeem et al., 2017; Amalraj and Gopi, 2017). 
Therefore, the present study focuses on identification of effective antibacterial compound from Terminalia arjuna and Andrographis paniculata using in silico analysis. The phytochemical compounds were retrieved from KnapSack database. Topo isomerase and DNA gyrase were the enzymes used as target proteins. The ADMET properties of the compounds were also determined.

\section{Materials and Methods}

\subsection{Preparation of target proteins}

The Staphylococcus aureus tyrosyl-tRNA synthetase (PDB ID: 1JIJ) and DNA gyrase subunit b (PDB ID: 1KZN) are used as target proteins in this research and the 3D structures were retrieved from the Protein Data Bank (http://www.rcsb.org/). Using PyMol tool the protein is visualized and then the protein bound water molecules, ligands and co-crystal ligands were eliminated (Figure 1). Further protein was prepared in auto dock tools, an open source software by introducing charges and energy minimization in Swiss PDB viewer and then converted to PDBQT format.

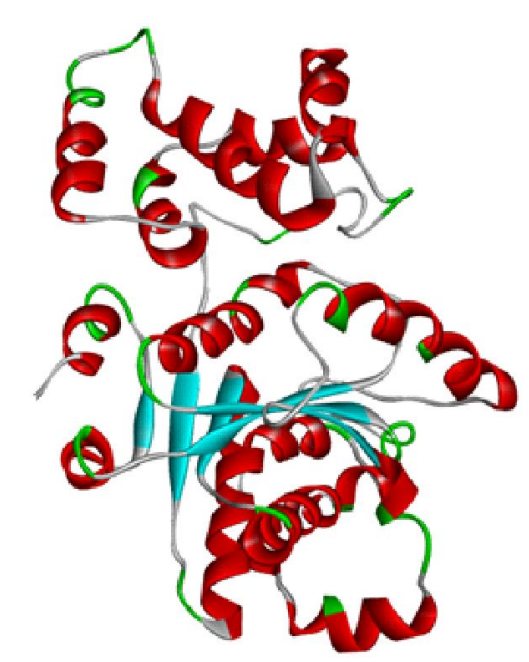

(a)

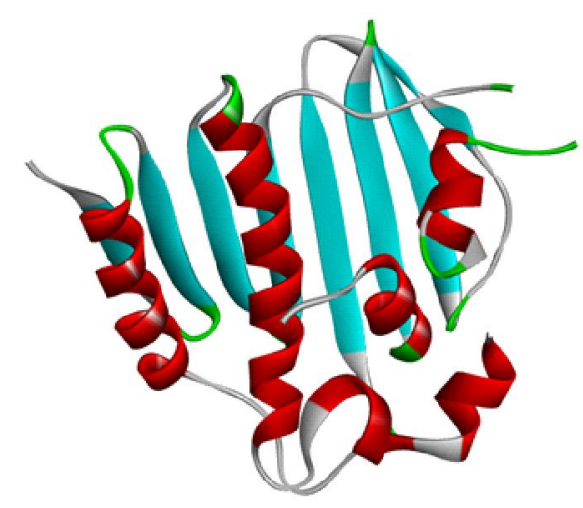

(b)

Figure 1: 3D structures of the target proteins. (a) Tyrosyl tRNA synthetase (b) DNA gyrase.

\subsection{Selection and preparation of ligands}

The phytochemical compounds present in T. arjuna and A. paniculata were identified and retrieved using KNApSAck database (http://www.knapsackfamily.com/KNApSAcK/). A total of 50 phytochemical compounds were used for the study. The preparation of ligand is carried out by detecting there torsion root, assigning charges, correcting the torsion angle, optimizing using UFF (universal force field) and then finally converted into pdbqt format to generate 3D atomic coordinates of the molecules (Rédei, 2008).

\subsection{Identification of active sites of target proteins}

Potential docking analysis requires accurate assessment of the active site. The amino acids in the active pocket site formation for target protiens were identified using the CASTp server (Computed Atlas for Surface Topography) (Sanjay Prasad and Shanthi, 2020; Tian et al., 2018). CASTp is a simple and useful online tool to analyze the protein topology and active site pockets. Active site determination is a vital part to set the grid box before docking.

\subsection{Screening of the of the ligands based on drug likeness}

The drug likeness of the compounds are evaluated using the online server Swiss ADME (http://swissadme.ch/index.php). Druglikeness of a compound is a necessary parameter to validate them as potential ligands against therapeutic targets (Daina et al., 2017). 50 phytochemical compounds were screened using the Lipinski's Rule of five and compounds showing drug likeness were used for docking studies.

\subsection{Molecular docking and protein-ligand interaction analysis}

The molecular docking of all the compound libraries was conducted using the PyRx tool by autodock wizard as the docking engine. Throughout the docking process, the ligands were assumed to be flexible and the protein was expected to be rigid. The grid parameter configuration file is generated using the grid box for $6 \mathrm{~W} 41(\mathrm{x}=-$ 12.59, $\mathrm{y}=-18.04, \mathrm{z}=83.05)$ and 6LU7 $(\mathrm{x}=17.27, \mathrm{y}=30.68, \mathrm{z}=$ 48.04) in PyRx, respectively (Dallakyan and Olson, 2015; Shanthipriya and Doss, 2012). After docking, the highest biding energy (most negative) was identified as the ligand with maximum binding affinity. The ligands exhibiting higher binding energy $(<-7 \mathrm{Kcal} / \mathrm{mol})$ were recognized and the ligand-protein interaction on the binding sites were analysed using Biovia Drug discovery studio 2019 .

\subsection{ADMET analysis of the selected ligands}

ADMET analysis involves evaluation of absorption, distribution, metabolism, excretion and toxicity levels of the selected compounds using online based algorithms.There are numerous online database and offline software applications which helps in predicting the drug candidates behaviour. In this study, we have used admetSAR (Cheng et al., 2012) for ADMET predictions. The compounds showing higher binding energies were examined for its human intestinal absorption, in vivo blood-brain barrier penetration, in vitro Caco-2 cell permeability, CYP450 2C9 substrate and toxicity parameters like mutagenicity by AMES test and carcinogenicity on rat were determined. Broad spectrum antibacterial drugs amoxicillin and ciprofloxacin are used as a standard drug to compare with the compounds. 


\section{Results}

\subsection{Druglikeness profiling of compounds}

The molecular and physical properties of the compounds play a key role in the identification of certain agents as a drug candidate. The compounds were filtered via Lipinski's five (Ro5) law to predict druglikeness. Lipinski's rule of five (Ro5) is a valuable parameter for determining the molecular properties of drug Table 1: Compounds showing druglikeness properties compounds and to estimate the essential pharmacokinetic parameters such as absorption, distribution, metabolism, and excretion for drug design and development (Lipinski et al., 2012). From this analysis, 46 out of 50 phytochemical compounds satisfied Lipinski's rule of five and the values were presented in the Table 1. The screened 46 compounds were subjected to molecular docking analysis.

\begin{tabular}{|c|c|c|c|}
\hline SI.No. & Compound name & Sl. No. & Compound name \\
\hline 1 & Norartocarpetin $5,7,2^{\prime}, 4^{\prime}$-tetramethyl ether & 24 & Dihydroskullcap flavone I \\
\hline 2 & Cerasidin & 25 & 14-Deoxyandrographolide \\
\hline 3 & Arjunone & 26 & Ninandrographolide \\
\hline 4 & Arjunolic acid & 27 & 14-Deoxy-11,14-didehydroandrographolide \\
\hline 5 & Caffeic acid & 28 & 14-Deoxy-11-oxoandrographolide \\
\hline 6 & Apigenin 7,4'-dimethyl ether & 29 & Andrograpanin \\
\hline 7 & 3-O-Caffeoylquinic acid & 30 & Neoandrographolide \\
\hline 8 & Ferulic acid & 31 & Andrographolide \\
\hline 9 & beta-Sitosterol & 32 & Andrographic acid \\
\hline 10 & 7-O-Methylwogonin & 33 & Cinnamic acid \\
\hline 11 & 5,4'-Dihidroxy-7,8,2',3'-tetramethox yflavone & 34 & 14-Acetyl-3,19-isopropylideneandrographolide \\
\hline 12 & Wogonin 5-glucoside & 35 & 14-Acetylandrographolide \\
\hline 13 & 5-Hydroxy-7,8-dimethoxyflavone 5-glucoside & 36 & $5,7,2^{\prime}, 3^{\prime}$-Tetramethoxyflavanone \\
\hline 14 & 5-Hydroxy-7,8,2'-trimethoxyflavone 5-glucoside & 37 & 12R,13R-Hydroxyandrographolide \\
\hline 15 & 5,2',3'-Trihydroxy-7,8-dimethoxyflavone 3'-glucoside & 38 & 12S,13S-Hydroxyandrographolide \\
\hline 16 & 5-Hydroxy-7,8,2',3'-tetramethoxyflavone 5-glucoside & 39 & 7R-Hydroxy-14-deoxyandrographolide \\
\hline 17 & 5-Hydroxy-7,8-dimethoxyflavanone & 40 & 7S-Hydroxy-14-deoxyandrographolide \\
\hline 18 & Andrographidin A & 41 & 12S-Hydroxyandrographolide \\
\hline 19 & Paniculide A & 42 & 14-Deoxy-17-hydroxyandrographolide \\
\hline 20 & Paniculide B & 43 & Andropanolide \\
\hline 21 & Paniculide C & 44 & Bisandrographolide B \\
\hline 22 & 5-Hydroxy-7,2',6'-trimethoxyflavone & 45 & Bisandrographolide $\mathrm{C}$ \\
\hline 23 & Skullcapflavone 1,2'-O-beta-D-glucopyranoside & 46 & isoandrographolide \\
\hline
\end{tabular}

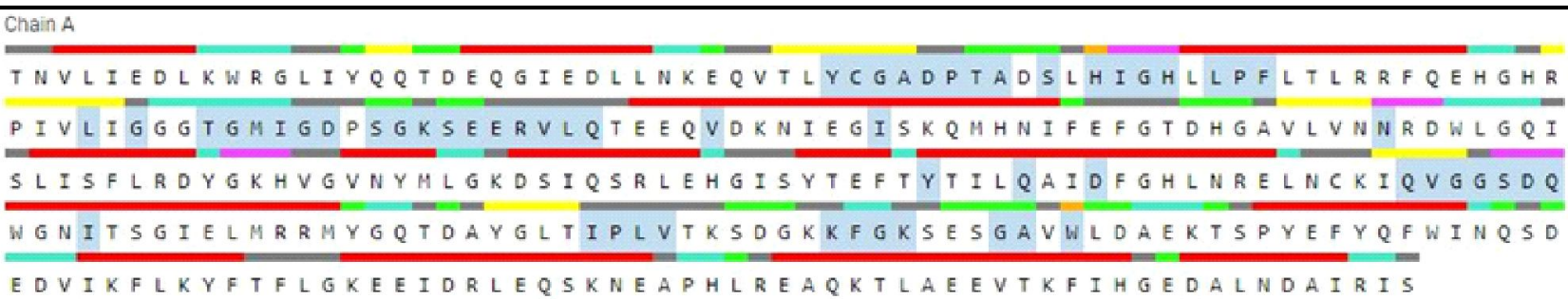

Figure 2: Binding sites of tyrosyl tRNA synthetase analysed using CASTp.

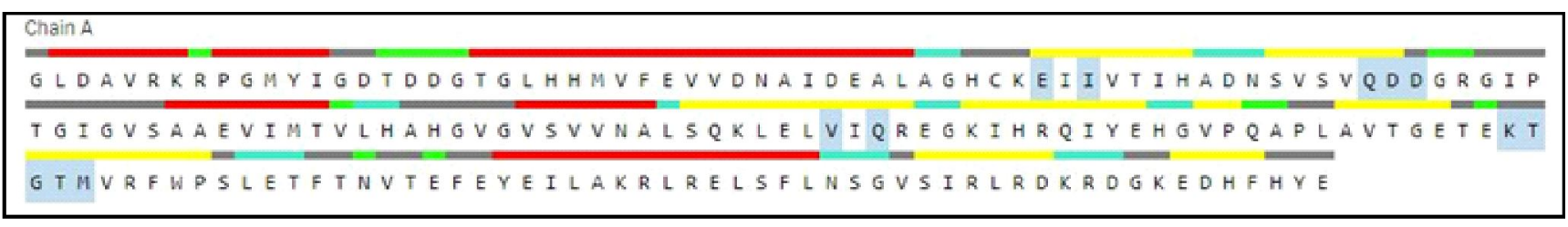

Figure 3: Binding sites of DNA gyrase analysed using CASTp. 
Table 2: Amino acid residues in the active sites

\begin{tabular}{|c|l|l|}
\hline SI. No. & Target protein & Amino acid residues in binding sites \\
\hline \multirow{2}{*}{ Tyrosyl-tRNA synthetase (PDB ID: 1JIJ) } & TYR-36, CYS-37, GLY-38, ALA-39, ASP-40, PRO-41, THR-42, ALA- \\
& & 43, SER-45, HIS-47, ILE-48, GLY-49, HIS-50, LEU-52, PRO-53, PHE- \\
& & 54, LEU-70, GLY-72, THR-75, GLY-76, MET-77, ILE-78, GLY-79, ASP- \\
& & 80, SER-82, GLY-83, LYS-84, SER-85, GLU-86, GLU-87, ARG-88, VAL- \\
& & 89, LEU-90, GLN-91, VAL-96, ILE-103, ASN-124, TYR-170, GLN-174, \\
& & ASP-177, GLN-190, 191-VAL, GLY-192, GLY-193, SER-194, ASP-195, \\
& & GLN-196, ILE-200, ILE-221, PRO-222, LEU-223, VAL-224, 231-LYS, \\
& & PHE-232, GLY-233, LYS-234, GLY-238, ALA-239, TRP-241 \\
\hline \multirow{2}{*}{2} & \multirow{2}{*}{ DNA gyrase (PDB ID: 1 KZN) } & GLU-58, ILE-60, GLN-72, ASP-73, ASP-74, VAL-133, GLN-135, LYS- \\
& & 162, THR-163, GLY-164, THR-165, MET-166 \\
\hline
\end{tabular}

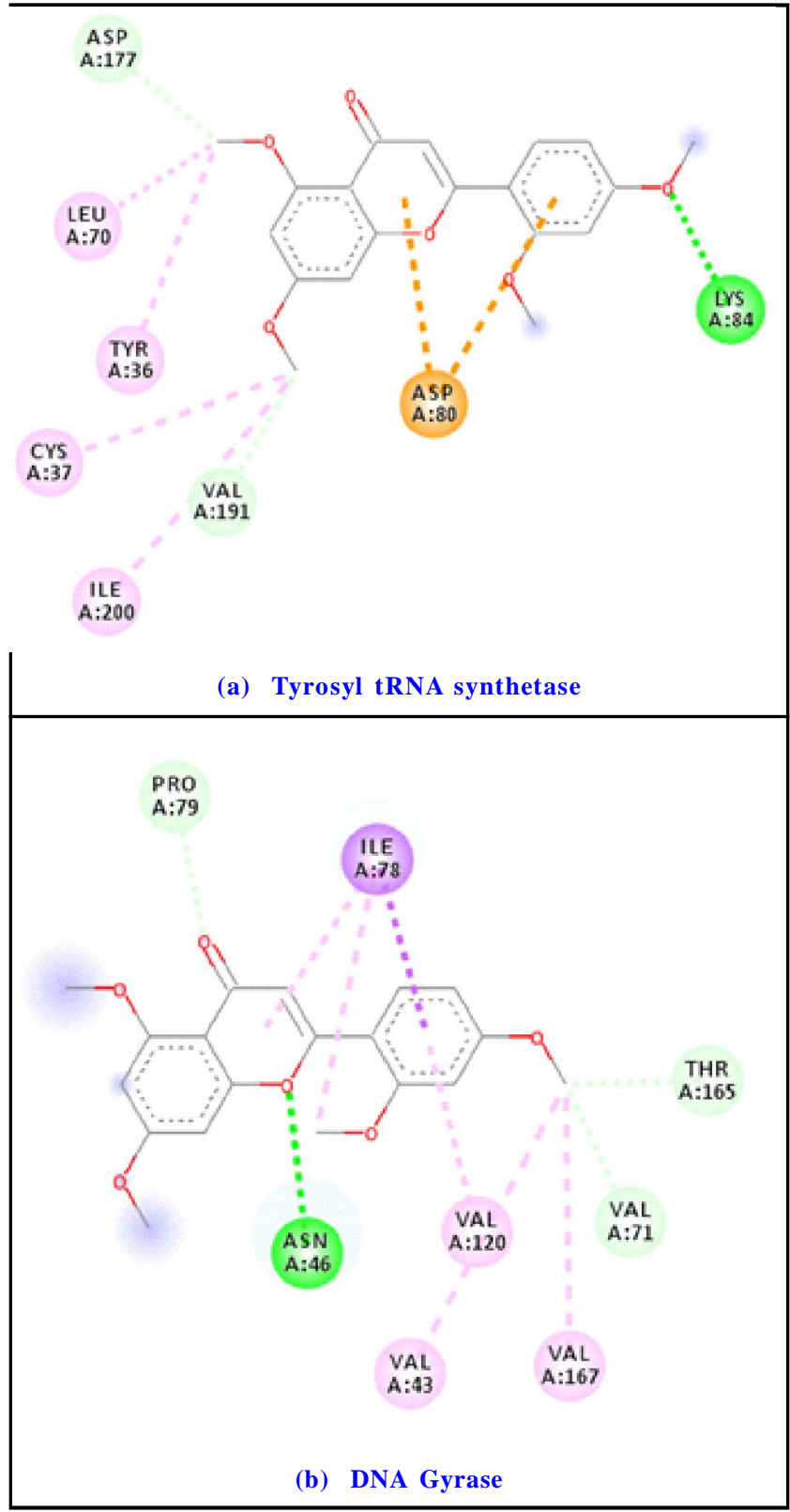

Figure 4: Interaction of norartocarpetin 5,7,2',4'-tetramethyl ether on target proteins.

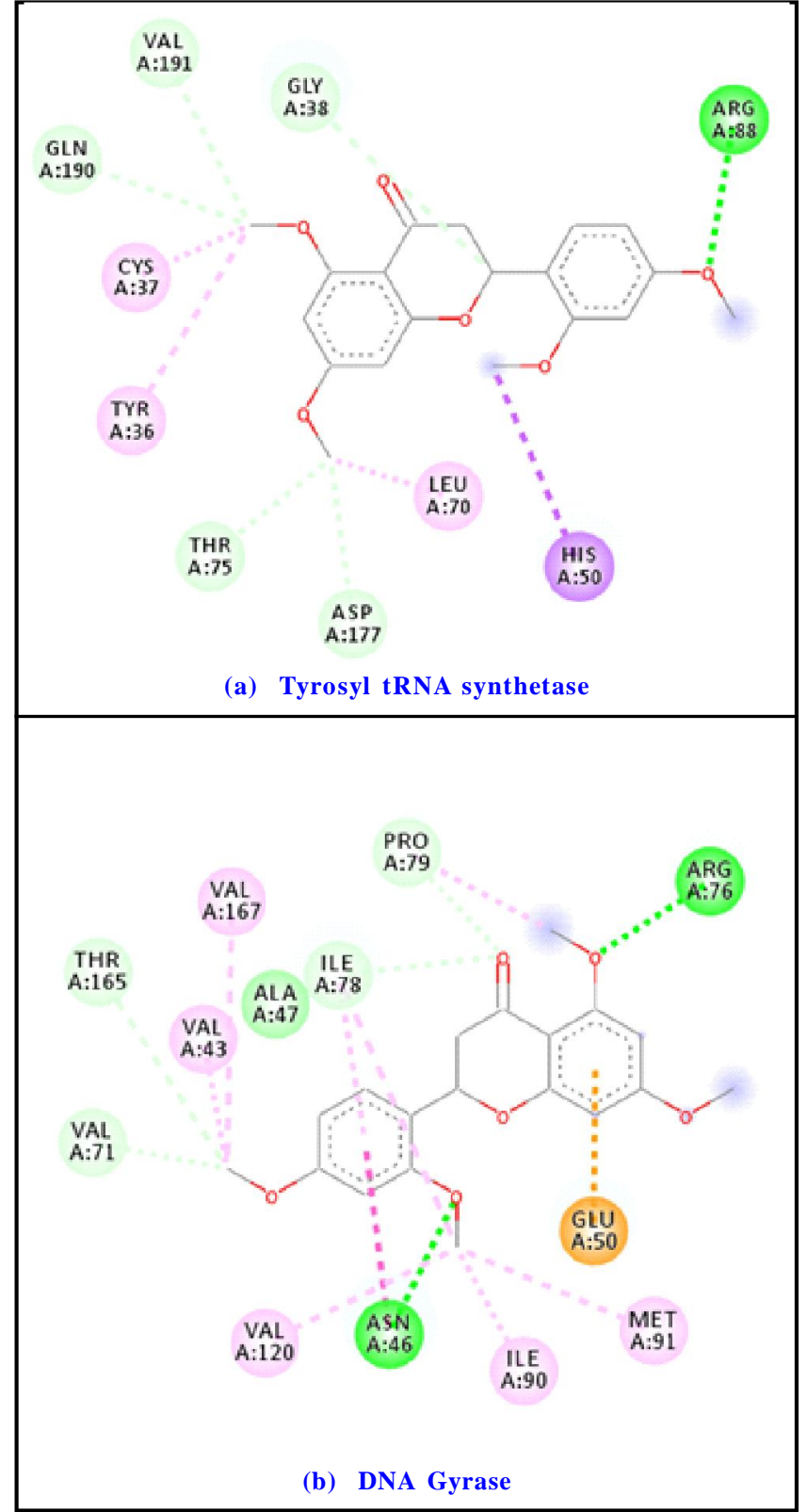

Figure 5: Interaction of arjunone on target proteins. 
Table 3: Binding energies of the compounds against the target proteins

\begin{tabular}{|c|c|c|c|}
\hline \multirow[t]{2}{*}{ SI. No. } & \multirow[t]{2}{*}{ Compound name } & \multicolumn{2}{|c|}{ Binding energy (kcal/mol) } \\
\hline & & 1JIJ & $1 \mathrm{KZN}$ \\
\hline 1 & Norartocarpetin $5,7,2^{\prime}, 4^{\prime}$-tetramethyl ether & -8.6 & -7.7 \\
\hline 2 & Cerasidin & -7.6 & -6.5 \\
\hline 3 & Arjunone & -8 & -7.5 \\
\hline 4 & Arjunolic acid & -7.3 & -6.1 \\
\hline 5 & Caffeic acid & -7.2 & -6.3 \\
\hline 6 & Apigenin $7,4^{\prime}$-dimethyl ether & -8.7 & -7.5 \\
\hline 7 & 3-O-Caffeoylquinic acid & -9.3 & -7.8 \\
\hline 8 & Ferulic acid & -6.9 & -6.2 \\
\hline 9 & beta-Sitosterol & -7.7 & -6 \\
\hline 10 & 7-O-Methylwogonin & -8.4 & -8.1 \\
\hline 11 & 5,4'-Dihidroxy-7,8,2',3'-tetramethox yflavone & -8.4 & -7 \\
\hline 12 & Wogonin 5-glucoside & -9.1 & -8.3 \\
\hline 13 & 5-Hydroxy-7,8-dimethoxyflavone 5-glucoside & -9.3 & -7.3 \\
\hline 14 & 5-Hydroxy-7,8,2'-trimethoxyflavone 5-glucoside & -9.1 & -7.6 \\
\hline 15 & 5,2',3'-Trihydroxy-7,8-dimethoxyflavone 3 '-glucoside & -9.5 & -6.9 \\
\hline 16 & 5-Hydroxy-3,7,8,2'-tetramethoxyflavone & -8.1 & -7.2 \\
\hline 17 & 5-Hydroxy-7,8-dimethoxyflavanone & -8.2 & -7.9 \\
\hline 18 & Andrographidin A & -9.1 & -8 \\
\hline 19 & Paniculide A & -7.7 & -7.8 \\
\hline 20 & Paniculide B & -7.9 & -8 \\
\hline 21 & Paniculide C & -8 & -7.8 \\
\hline 22 & 5-Hydroxy-7,2',6'-trimethoxyflavone & -8.1 & -7.5 \\
\hline 23 & Skullcapflavone 1,2'-O-beta-D-glucopyranoside & -9.6 & -7.8 \\
\hline 24 & Dihydroskullcap flavone I & -8.7 & -7.8 \\
\hline 25 & 14-Deoxyandrographolide & -7.6 & -7 \\
\hline 26 & Ninandrographolide & -10 & -7.3 \\
\hline 27 & 14-Deoxy-11,14-didehydroandrographolide & -7.7 & -7.1 \\
\hline 28 & 14-Deoxy-11-oxoandrographolide & -8.8 & -6.6 \\
\hline 29 & Andrograpanin & -8 & -7 \\
\hline 30 & Neoandrographolide & -7.7 & -7.4 \\
\hline 31 & Andrographolide & -8.6 & -7.1 \\
\hline 32 & Andrographic acid & -7.5 & -7.2 \\
\hline 33 & Cinnamic acid & -6.4 & -5.8 \\
\hline 34 & 14-Acetyl-3,19-isopropylideneandrographolide & -10.1 & -7.4 \\
\hline 35 & 14-Acetylandrographolide & -8.7 & -6.7 \\
\hline 36 & $5,7,2^{\prime}, 3^{\prime}$-Tetramethoxyflavanone & -7.9 & -6.8 \\
\hline 37 & 12R,13R-Hydroxyandrographolide & -7.8 & -7.2 \\
\hline 38 & 12S,13S-Hydroxyandrographolide & -7.8 & -7.1 \\
\hline 39 & 7R-Hydroxy-14-deoxyandrographolide & -7.6 & -6.7 \\
\hline 40 & 7S-Hydroxy-14-deoxyandrographolide & -7.8 & -6.5 \\
\hline 41 & 12S-Hydroxyandrographolide & -8 & -6.4 \\
\hline 42 & 14-Deoxy-17-hydroxyandrographolide & -8.4 & -7.2 \\
\hline 43 & Andropanolide & -8.1 & -7.1 \\
\hline 44 & Bisandrographolide B & -8.3 & -5.7 \\
\hline 45 & Bisandrographolide $\mathrm{C}$ & -8.6 & -6.7 \\
\hline 46 & Isoandrographolide & -8 & -6.7 \\
\hline
\end{tabular}




\subsection{Binding site analysis and molecular docking}

Active site pockets in tyrosyl-tRNA synthetase and DNA gyrase were determined using CASTp. CASTp is a web-based tool to determine the amino acid residues in the active pocket of the proteins. CASTp results are depicted in Figure 2 for tyrosyl-tRNA synthetase and Figure 3 for DNA gyrase. From CASTp results, only the amino acids in the active site and their positions are listed as Table 2. Grid box were generated covering the binding sites of the target protein

Table 4: Protein-ligand interactions

\begin{tabular}{|c|c|c|c|c|c|}
\hline \multirow{2}{*}{ Sl. No. } & \multirow{2}{*}{ Cpd name } & \multicolumn{2}{|r|}{ 1JIJ } & \multicolumn{2}{|c|}{$1 \mathrm{KZN}$} \\
\hline & & $\begin{array}{l}\text { No of } \mathrm{H}- \\
\text { bond }\end{array}$ & Binding amino acid residue & No of H-bond & $\begin{array}{l}\text { Binding amino acid } \\
\text { residue }\end{array}$ \\
\hline 1 & Norartocarpetin 5,7,2',4'-tetramethyl ether & 1 & LYS-84 & - & - \\
\hline 2 & Arjunone & 1 & ARG-88 & - & - \\
\hline 3 & Apigenin 7,4'-dimethyl ether & 5 & TYR-36, CYS-37, LYS-84, ARG-88, VAL-191 & 1 & ASP-73 \\
\hline 4 & 3-O-Caffeoylquinic acid & 7 & $\begin{array}{l}\text { TYR-36, CYS-37, HIS-50, THR-75, LYS-84, } \\
\text { GLN-174, GLN-190 }\end{array}$ & 1 & THR-165 \\
\hline 5 & 7-O-Methylwogonin & 1 & CYS-37 & 1 & ASP-73 \\
\hline 6 & 5,4'-Dihidroxy-7,8,2',3'-tetramethoxyflavone & 3 & CYS-37, HIS-50, VAL-191 & 1 & THR-165 \\
\hline 7 & Wogonin 5-glucoside & 4 & TYR-36, CYS-37, GLY-38, GLN-190 & 2 & THR-165 \\
\hline 8 & 5-Hydroxy-7,8-dimethoxyflavone 5-glucoside & 7 & $\begin{array}{l}\text { TYR-36, CYS-37, GLY-38, ASP-40, THR-75, } \\
\text { TYR-170, GLN-190 }\end{array}$ & 2 & THR-165 \\
\hline 9 & 5-Hydroxy-7,8,2'-trimethoxyflavone 5-glucoside & 5 & CYS-37, GLY-38, ASP-40, THR-75, TYR-170 & 1 & THR-165 \\
\hline 10 & 5-Hydroxy-3,7,8,2'-tetramethoxyflavone & 2 & CYS-37, GLY-193 & - & - \\
\hline 11 & 5-Hydroxy-7,8-dimethoxyflavanone & 2 & ASP-40, GLN-196 & - & - \\
\hline 12 & Andrographidin A & 6 & $\begin{array}{l}\text { CYS- } 37 \text {, HIS-47, HIS-50, SER-82, LYS-84, } \\
\text { GLY- } 193\end{array}$ & 2 & ASP-73 \\
\hline 13 & Paniculide A & 2 & ASP-40, TYR-170 & 1 & THR-165 \\
\hline 14 & Paniculide B & 4 & GLY-38, THR-75, TYR-170, GLN-174 & 1 & THR-165 \\
\hline 15 & Paniculide C & 2 & TYR-170, GLN-174 & 1 & THR-165 \\
\hline 16 & 5-Hydroxy-7,2',6'-trimethoxyflavone & 1 & CYS-37 & 1 & THR-165 \\
\hline 17 & Skullcapflavone 1,2'-O-beta-D-glucopyranoside & 2 & GLY-38, ASP-195 & 1 & ASP-73 \\
\hline 18 & Dihydroskullcap flavone I & 4 & CYS-37, ASP-80, VAL-191, GLN-196 & 1 & ASP-73 \\
\hline 19 & 14-Deoxyandrographolide & 3 & HIS-50, THR-75, TYR-170 & 1 & THR-165 \\
\hline 20 & Ninandrographolide & 5 & TYR-36, GLY-38, ASP-40, THR-75, ASP-177 & 1 & ASP-73 \\
\hline 21 & 14-Deoxy-11,14-didehydroandrographolide & 2 & TYR-170, GLN-174 & - & - \\
\hline 22 & Andrograpanin & & THR-75, TYR-170 & 1 & THR-165 \\
\hline 23 & Neoandrographolide & 6 & ASP-40, ASP-80 LYS-84, GLN-196 & 2 & ASP-73 \\
\hline 24 & Andrographolide & 3 & GLN-174, GLY-193, GLN-196 & 1 & GLN-135 \\
\hline 25 & Andrographic acid & 1 & GLN-196 & 4 & $\begin{array}{l}\text { GLN-72, ASP-73, } \\
\text { GLN-135 }\end{array}$ \\
\hline 26 & 14-Acetyl-3,19-isopropylideneandrographolide & 3 & THR-75, TYR-170, GLN-174 & 1 & GLN-135 \\
\hline 27 & 12R,13R-Hydroxyandrographolide & 3 & GLY-38, ASP-40, ASP-195 & - & - \\
\hline 28 & 12S,13S-Hydroxyandrographolide & 3 & TYR-36,GLY-38, ASP-195 & 1 & ASP-73 \\
\hline 29 & 14-Deoxy-17-hydroxyandrographolide & 2 & GLY-38, GLN-174 & - & - \\
\hline 30 & Andropanolide & 1 & ASP-40 & 2 & ASP-73, THR-165 \\
\hline
\end{tabular}

PyRx was used for performing docking analysis for all 46 compounds against their target proteins tyrosyl-tRNA synthetase and DNA gyrase. Binding energies of the compounds were analyzed and the compounds showing higher binding energy $(<-7.0 \mathrm{Kcal} /$ mol) against both RBD and protease were identified. About 30 compounds showed significant binding energy $(<-7.0 \mathrm{Kcal} / \mathrm{mol})$ for both the targets and the compounds are shown in the Table 3 .

\subsection{Protein-ligand interaction analysis}

The best-docked compounds were further analyzed for binding interactions with amino acid residues using Biovia Accelrys Discovery Studio Visualizer software. Bonding type, number of hydrogen bonds and hydrophobic interactions are a very important determinant of protein-ligand interactions as well as binding affinity. The number of hydrogen bonds formed and amino acids involved in 
the interactions are tabulated in Table 4. The hydrogen bonds and other hydrophobic interactions of the ligands on the binding sites of the target proteins were shown in the Figures 4 to 33 . All the 30 compounds showed $\mathrm{H}$-bond formation on binding sites of the target proteins except norartocarpetin 5,7,2',4'- tetramethyl ether, arjunone, 5-hydroxy-3,7,8,2' - tetramethoxyflavone, 5-hydroxy7,8-dimethoxyflavanone, 14-deoxy-11,14-didehydroandrographolide, 12R,13R-hydroxyandrographolide and 14-deoxy-17hydroxyandrographolide. These compounds failed to show H-bond on binding sites of DNA gyrase. Therefore, the remaining 23 compounds were subjected to ADMET analysis to find out significant compounds for development of novel Antibacterial drugs.

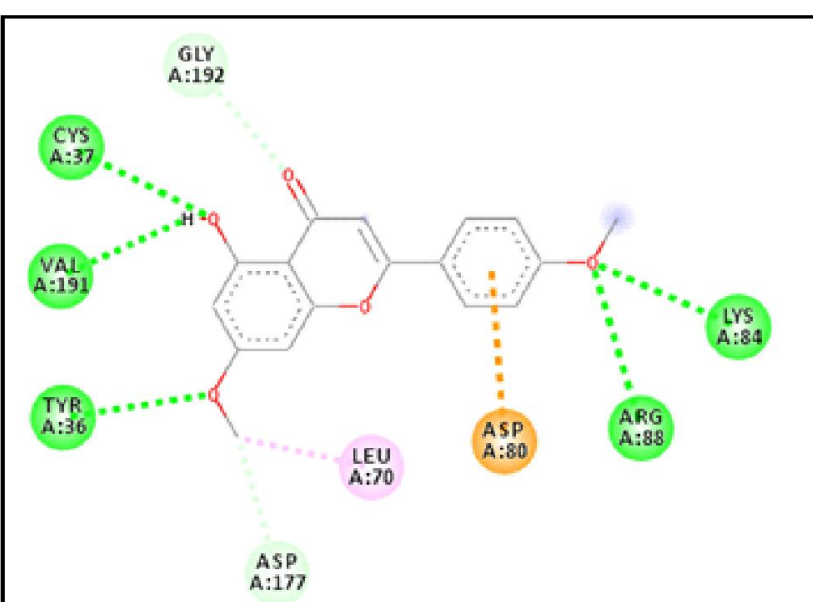

(a) Tyrosyl tRNA synthetase

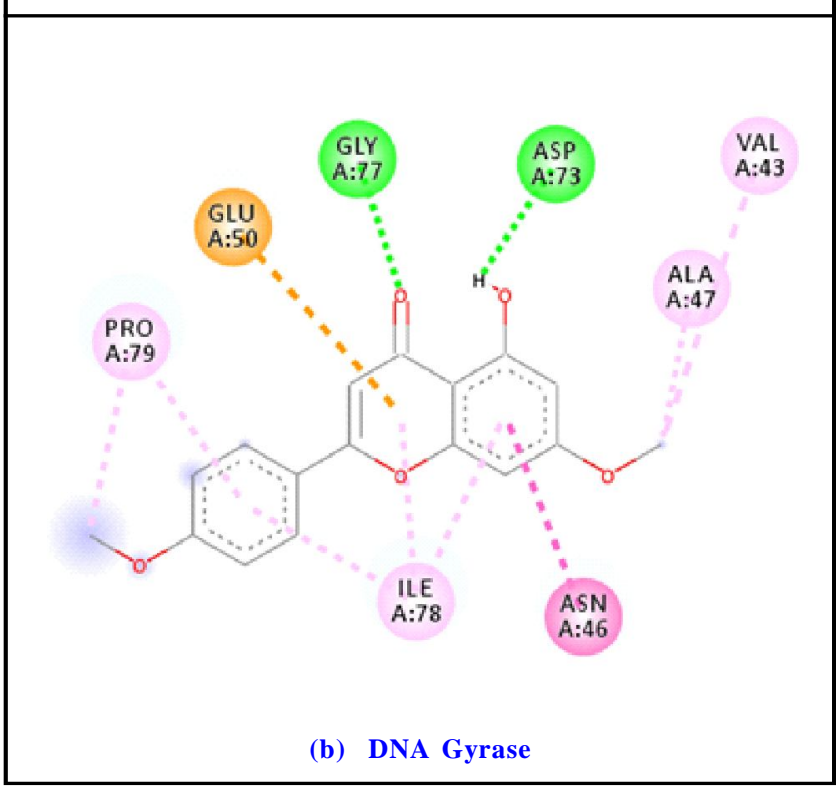

Figure 6: Interaction of Apigenin 7, 4'- dimethyl ether on target proteins.

\subsection{ADMET properties}

ADMET properties of the compounds interact with the absorption, distribution, metabolism, excretion and toxicity in and across the human body. ADMET defines the pharmacokinetic properties of the drug molecule and it is very important in assessing its pharmacodynamic activity. Amoxicillin is used as control drug for comparison. Amoxicillin showed BBB, HIA, in vitro Caco-2 permeability, distribution and non-substrate of CYP450 2C9 values of $0.99,0.90,0.87,0.48$ and 0.84 . Other compounds like andrographolide, 14-Acetyl-3,19-isopropylideneandrographolide, andropanolide, 5-hydroxy-7,8-dimethoxyflavone 5-glucoside, andrograpanin and andrographic acid showed significant ADME values. From the toxicity analysis, AMES toxicity and mutagenicity of the compounds were determined. All the compounds were found to be non-mutagenic and all the compounds except paniculide A, paniculide $\mathrm{B}$ and paniculide $\mathrm{C}$ were non AMES toxic.

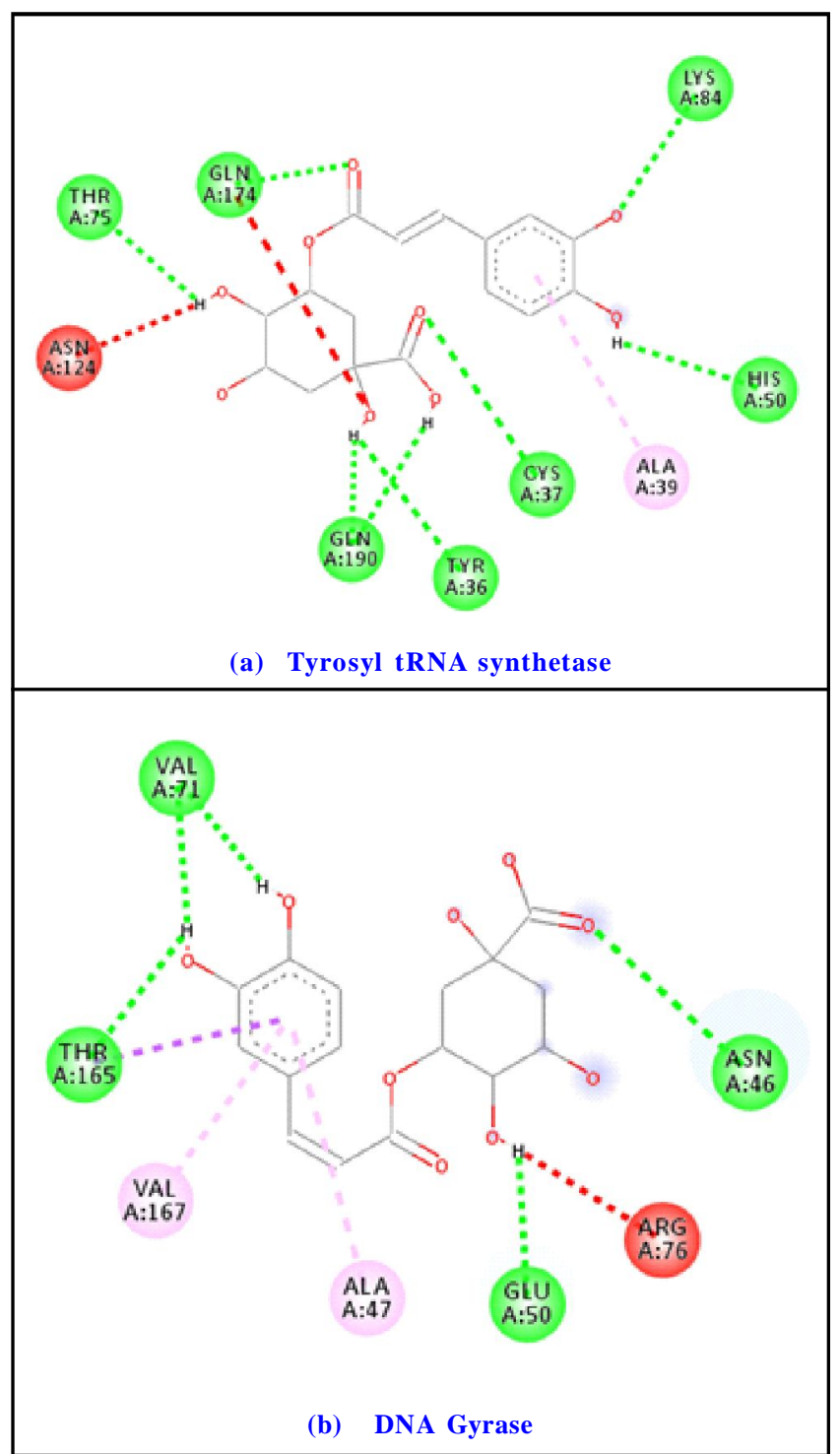

Figure 7: Interaction of 3-O-caffeoylquinic acid on target proteins.

\section{Discussion}

Phytochemicals serves as a first line of source for the discovery of new drugs. In the search of new antimicrobials, phytochemicals can be the best solution in context of bioavailability and less toxicity. 
Natural based drugs show less toxicity on comparing to synthetic drugs (Padayachee and Baijnath, 2020; Paritala et al., 2015). Since there are millions of phytochemicals available, in silico studies paves way for quick and effective screening of best compounds. An effective compound with target specificity and better ADMET properties can be identified. Thus, in silico screening is the best technique for identification of new drugs (Bintener et al., 2020).

In the current scenario, several drug resistant bacterial pathogens have been evolved with their specific resistance mechanisms leading to ineffective antibiotics and threating the whole world. The world health organisation (WHO) had declared antimicrobial resistance (AMR) as an emerging crisis in the world and there is need for the development of new antimicrobial agents/therapies to overcome AMR (Aslam et al., 2018). In the present study, phytochemical compounds from T. arjuna and A. paniculata were screened for the antibacterial action against novel bacterial targets tyrosyl-tRNA synthetase and DNA gyrase.

Bacterial gyrase focused therapeutics is exclusive because it is the universal enzyme required for the survival of bacterial and is missing in higher eukaryotes. DNA gyrase (gyrase), a bacterial topoisomerase, is known to regulate DNA-dependent processes by introducing transient breaks in both DNA strands and relieving torsional stress in the DNA molecule by introducing negative supercoils. DNA gyrase is a heterotetrameric protein made up of two GyrA subunits that contain the DNA cleavage site and two GyrB subunits that provide the energy for the enzyme's catalytic function by hydrolyzing ATP. Thus, drugs that target bacterial topoisomerases function in one of two ways: either by stabilising the complex between the DNA molecule and the enzyme's GyrA active site (e.g., quinolones) or by inhibiting the GyrB subunit's ATPase activity (e.g., aminocoumarin class of inhibitors) (Collin et al., 2011).

Amino acyl-tRNA synthetases (aaRSs) are a type of significant enzymes that catalyse the transport of amino acids to their corresponding tRNAs during protein synthesis. They are necessary to translate coded information into protein structures in nucleic acids since they recognise these information, which includes coincident tRNA molecules and amino acid structures. TyrRS are present in all living species as members of the aaRS family. TyrRS is a member of the class I tRNA synthetase family, which has two strongly symmetric sequence motifs, HIGH and KMSKS, at the active site. TyrRS in bacteria and TyrRS in humans vary in a number of ways. Small-molecule TyrRS inhibitors with these properties may be promising drug candidates for high selectivity and broadspectrum antibacterial agents. TyrRS plays an important role in protein biosynthesis, and inhibiting these enzymes is harmful to cells. TyrRS is also highly conserved among prokaryotes, making it a good target for the production of broad-spectrum antibiotics (Skupiñska et al., 2017).

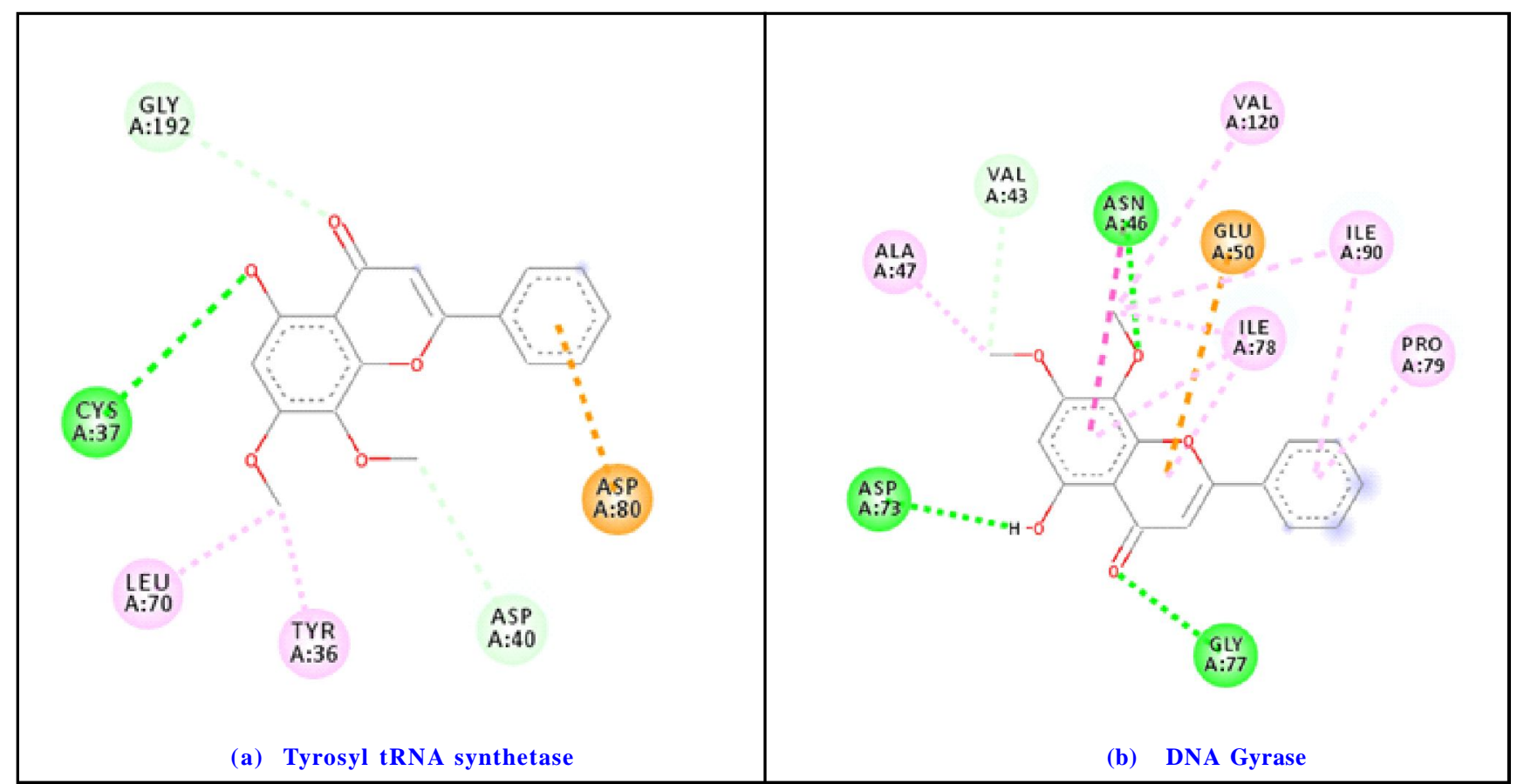

Figure 8: Interaction of 7-O-methylwogonin on target proteins.

50 compounds extracted from KNApSAck database were preliminarily screened for druglikeness analysis using Lipinski rule of 5 (RO5). 46 compounds showed Druglikeness and these compounds were subjected to docking against the dual targets. Compounds showing higher binding energies $(>-7 \mathrm{kcal} / \mathrm{mol})$ were investigated for protein-ligand interaction. Interaction of ligands on binding sites of the targets proteins are very much essential on comparing with the higher binding energies. Formation of H-bonds proves the stability of the docked complex. Therefore, the, H-bond formation on binding sites of the target proteins was evaluated. 23 compounds showed significant interactions with $\mathrm{H}$-bonds and those compounds were further examined for ADMET analysis.

The significant compounds showing higher binding energies to both the targets (>-7 kcal/mol), druglikeness and better ADME properties 
with no toxicity and mutagenicity were found to be andropanolide, andrographidin A, ninandrographolide, andrograpanin, neoandrographolide, andrographolide, apigenin 7,4'-dimethyl ether, 3-O-caffeoylquinic acid, 7-O-methylwogonin, 5,4'-dihidroxy7,8,2',3'-tetramethoxyflavone, wogonin 5-glucoside, 5-hydroxy-7,8dimethoxyflavone 5-glucoside, 5-hydroxy-7,8,2'-trime thoxyflavone 5-glucoside, 5-hydroxy-7,2',6'-trimethoxy-flavone, Skullcapflavone 1,2'-O-beta-d-glucopyranoside, dihydroskullcap flavone I, 14-Deoxyandrographolide, 14-Acetyl-3,19-isopropylideneandro grapholide, 12S,13S-hydroxyandrogra-pholide. All these compounds were present in A. paniculata. Several studies report the antimicrobial activity of $A$. paniculata. A. paniculata showed higher inhibition activity against several bacterial pathogens like Escherichia coli, Pseudomonas aeruginosa, Clostridium perfringens, Serratia marcescens, Bacillus subtilis, Enterobacter aerogenes, Shigella flexneri, Staphylococcus aureus and Salmonella typhi (Tandon et al., 2015).

Table 5: ADME analysis of the selected compounds

\begin{tabular}{|c|c|c|c|c|c|c|}
\hline Sl. No. & Plant compounds & $\begin{array}{l}\text { In vivo blood- } \\
\text { brain barrier } \\
\text { penetration } \\
\text { (C.brain/C. blood) }\end{array}$ & $\begin{array}{c}\text { Human } \\
\text { intestinal } \\
\text { absorption } \\
\quad(\%)\end{array}$ & $\begin{array}{c}\text { In vitro } \\
\text { Caco-2 cell } \\
\text { permeabilit } \\
\text { y }(\mathrm{nm} / \mathrm{sec})\end{array}$ & Distribution & $\begin{array}{c}\text { CYP } 450 \\
2 \text { C9 }\end{array}$ \\
\hline 1 & Amoxicillin & 0.99 & 0.90 & 0.87 & 0.48 & NS $(0.84)$ \\
\hline 2 & Apigenin 7,4'-dimethyl ether & 0.70 & 0.99 & 0.92 & 0.67 & NS (0.77) \\
\hline 3 & 3-O-Caffeoylquinic acid & 0.56 & 0.74 & 0.80 & 0.67 & NS (0.79) \\
\hline 4 & 7-O-Methylwogonin & 0.71 & 0.99 & 0.91 & 0.78 & NS (0.77) \\
\hline 5 & $\begin{array}{l}\text { 5,4'-Dihidroxy-7,8,2',3'- } \\
\text { tetramethoxyflavone }\end{array}$ & 0.59 & 0.98 & 0.89 & 0.79 & NS (0.78) \\
\hline 6 & Wogonin 5-glucoside & 0.92 & 0.77 & 0.89 & 0.61 & NS $(0.76)$ \\
\hline 7 & $\begin{array}{l}\text { 5-Hydroxy-7,8- } \\
\text { dimethoxyflavone 5-glucoside }\end{array}$ & 0.93 & 0.72 & 0.89 & 0.62 & NS (0.79) \\
\hline 8 & $\begin{array}{l}\text { 5-Hydroxy-7,8,2'- } \\
\text { trimethoxyflavone 5-glucoside }\end{array}$ & 0.94 & 0.70 & 0.88 & 0.60 & NS (0.78) \\
\hline 9 & Andrographidin A & 0.93 & 0.72 & 0.89 & 0.62 & NS (0.79) \\
\hline 10 & Paniculide A & 0.93 & 0.96 & 0.52 & 0.70 & NS (0.79) \\
\hline 11 & Paniculide B & 0.80 & 0.97 & 0.58 & 0.82 & NS $(0.84)$ \\
\hline 12 & Paniculide C & 0.88 & 0.98 & 0.59 & 0.84 & NS $(0.85)$ \\
\hline 13 & $\begin{array}{l}\text { 5-Hydroxy-7,2',6'- } \\
\text { trimethoxyflavone }\end{array}$ & 0.74 & 0.99 & 0.94 & 0.80 & NS $(0.74)$ \\
\hline 14 & $\begin{array}{l}\text { Skullcapflavone 1,2'-O-beta-D- } \\
\text { glucopyranoside }\end{array}$ & 0.93 & 0.72 & 0.89 & 0.62 & NS (0.79) \\
\hline 15 & Dihydroskullcap flavone I & 0.59 & 0.96 & 0.85 & 0.81 & $\mathrm{NS}(0.76)$ \\
\hline 16 & 14-Deoxyandrographolide & 0.80 & 0.92 & 0.61 & 0.66 & NS (0.82) \\
\hline 17 & Ninandrographolide & 0.55 & 0.53 & 0.88 & 0.77 & NS (0.87) \\
\hline 18 & Andrograpanin & 0.92 & 0.98 & 0.61 & 0.64 & NS (0.78) \\
\hline 19 & Neoandrographolide & 0.51 & 0.51 & 0.88 & 0.80 & NS (0.87) \\
\hline 20 & Andrographolide & 0.81 & 0.91 & 0.67 & 0.70 & NS (0.83) \\
\hline 21 & Andrographic acid & 0.76 & 0.89 & 0.51 & 0.80 & NS (0.85) \\
\hline 22 & $\begin{array}{l}\text { 14-Acetyl-3,19- } \\
\text { isopropylideneandrographolide }\end{array}$ & 0.90 & 0.93 & 0.62 & 0.83 & NS (0.89) \\
\hline 23 & $\begin{array}{l}\text { 12S,13S- } \\
\text { Hydroxyandrographolide }\end{array}$ & 0.81 & 0.91 & 0.67 & 0.70 & NS (0.83) \\
\hline 24 & Andropanolide & 0.83 & 0.97 & 0.74 & 0.81 & NS (0.85) \\
\hline
\end{tabular}

\footnotetext{
*NS-non-substrate
} 


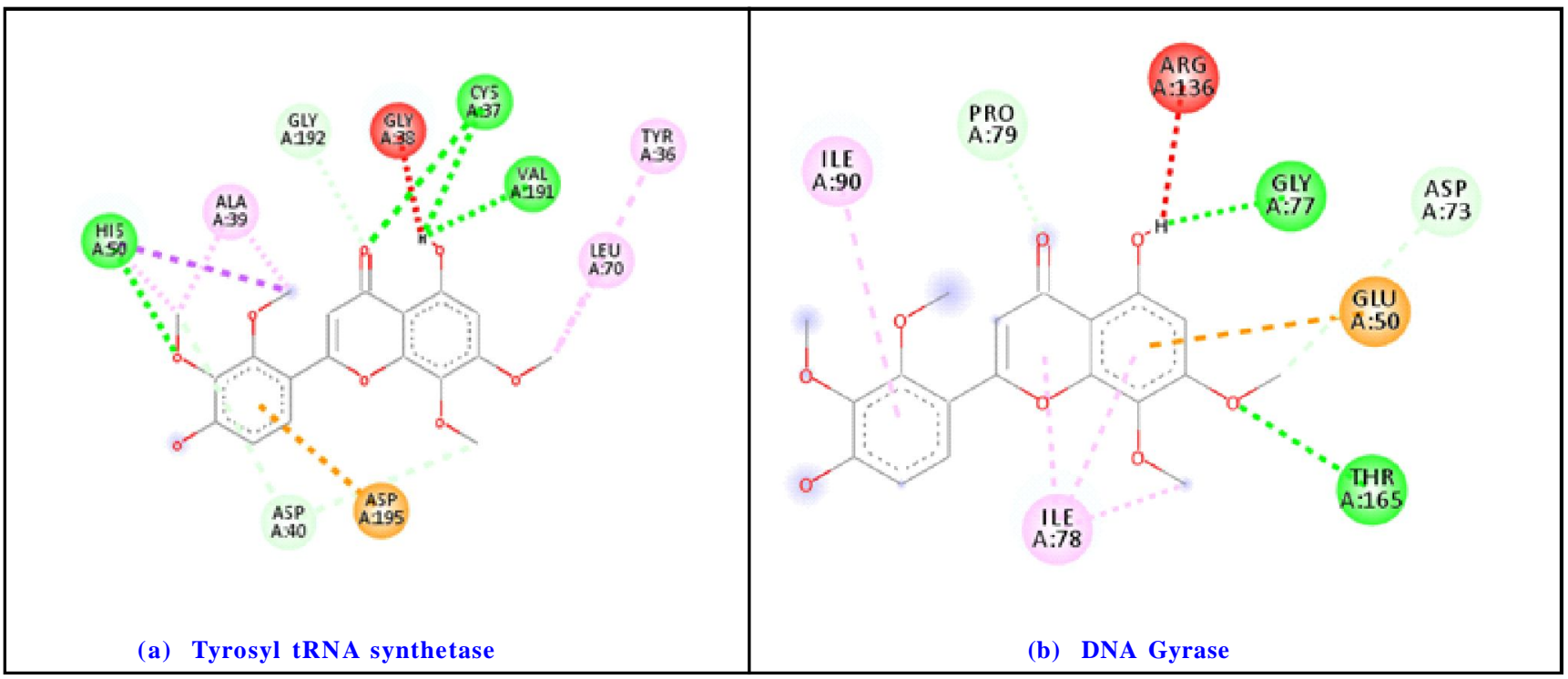

Figure 9: Interaction of 5,4'-dihidroxy-7,8,2',3'-tetramethoxyflavone on target proteins.

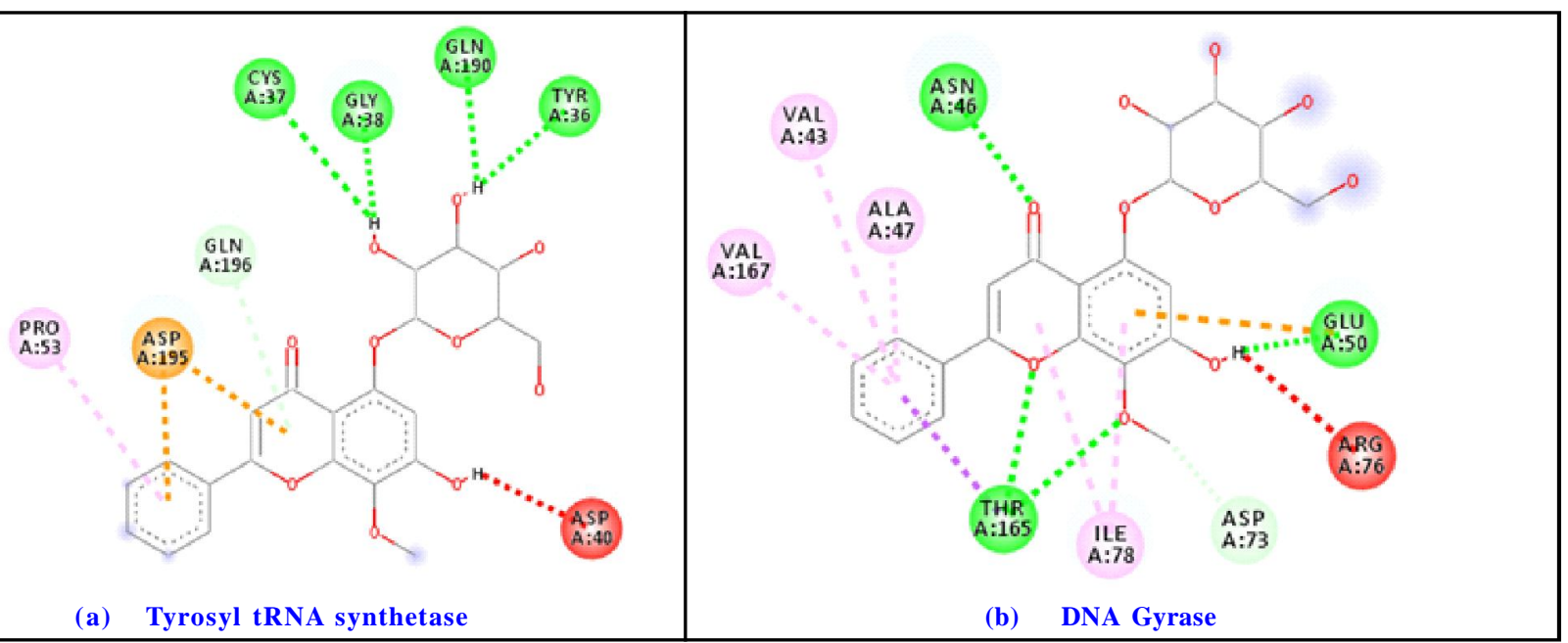

Figure 10: Interaction of wogonin 5-glucoside on target proteins.

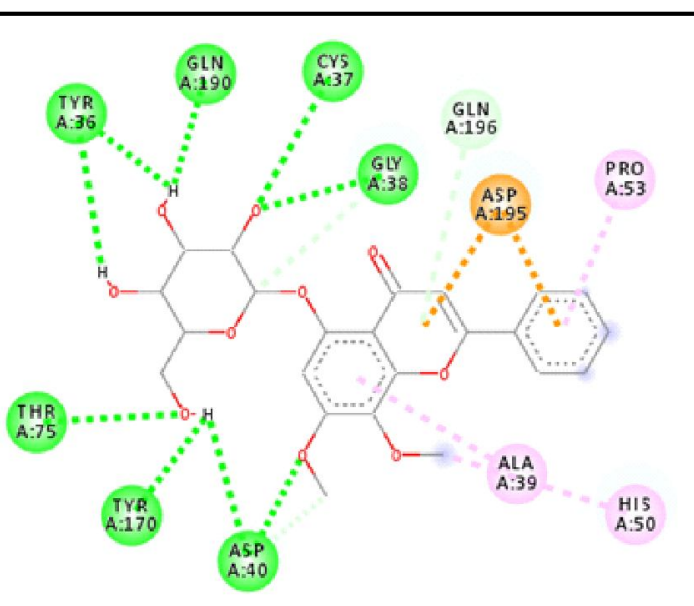

(a) Tyrosyl tRNA synthetase

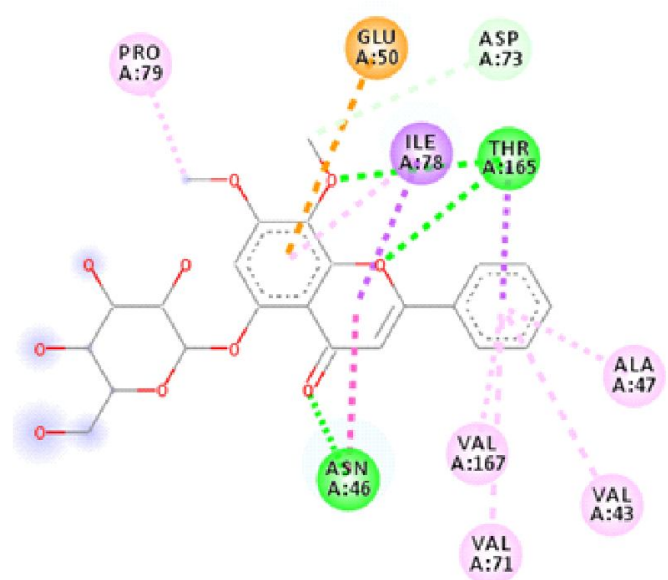

(b) DNA Gyrase

Figure 11: Interaction of 5-Hydroxy-7,8-dimethoxyflavone 5-glucoside on target proteins. 


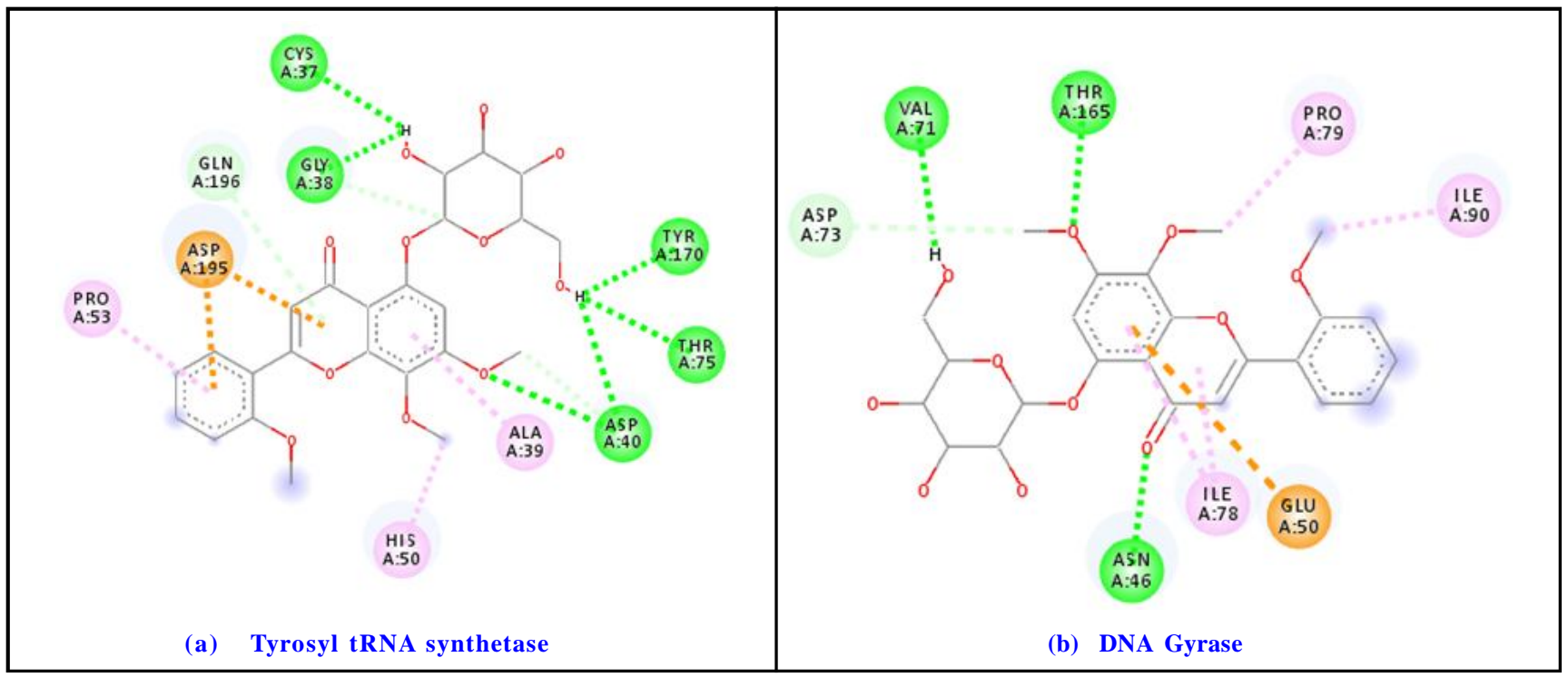

Figure 12: Interaction of 5-hydroxy-7,8,2'-trimethoxyflavone 5-glucoside on target proteins.

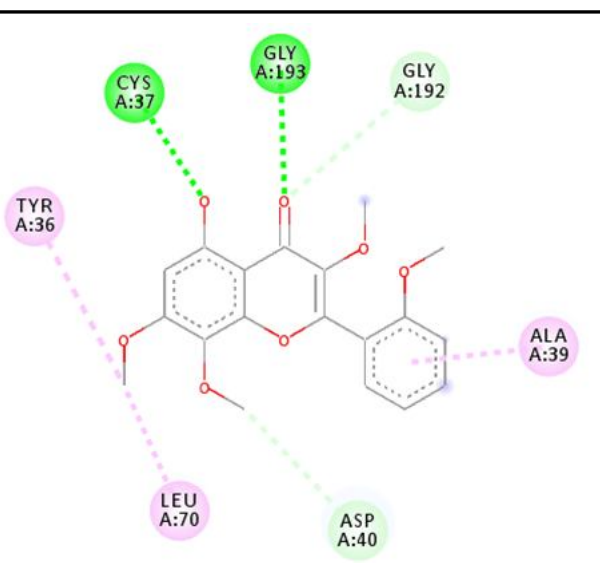

(a) Tyrosyl tRNA synthetase

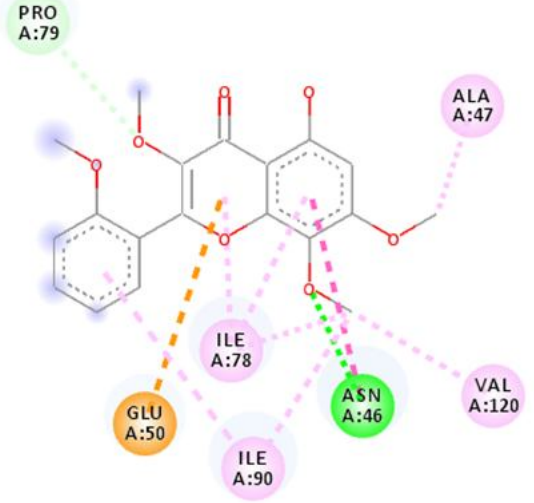

(b) DNA Gyrase

Figure 13: Interaction of 5-hydroxy-3,7,8,2'-tetramethoxyflavone on target proteins.

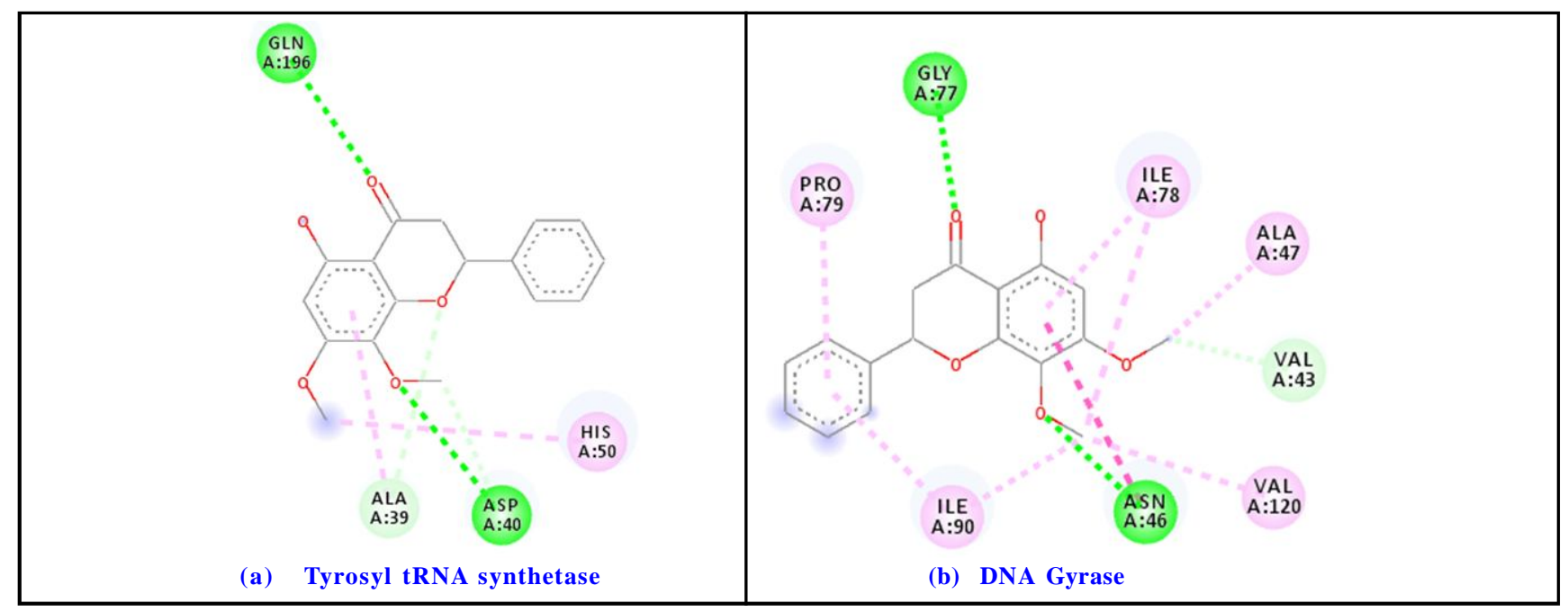

Figure 14: Interaction of 5-hydroxy-7,8-dimethoxyflavanone on target proteins. 


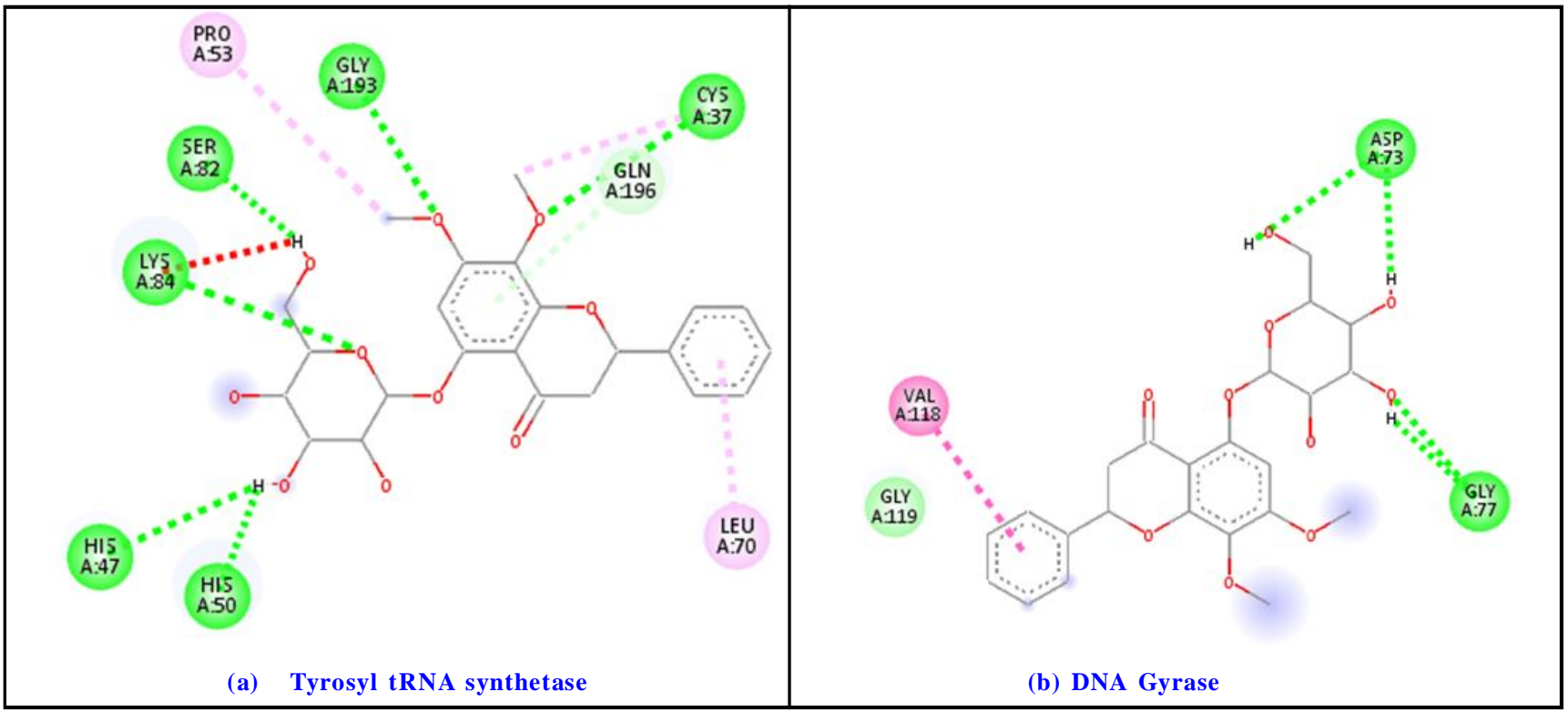

Figure 15: Interaction of andrographidin A on target proteins.

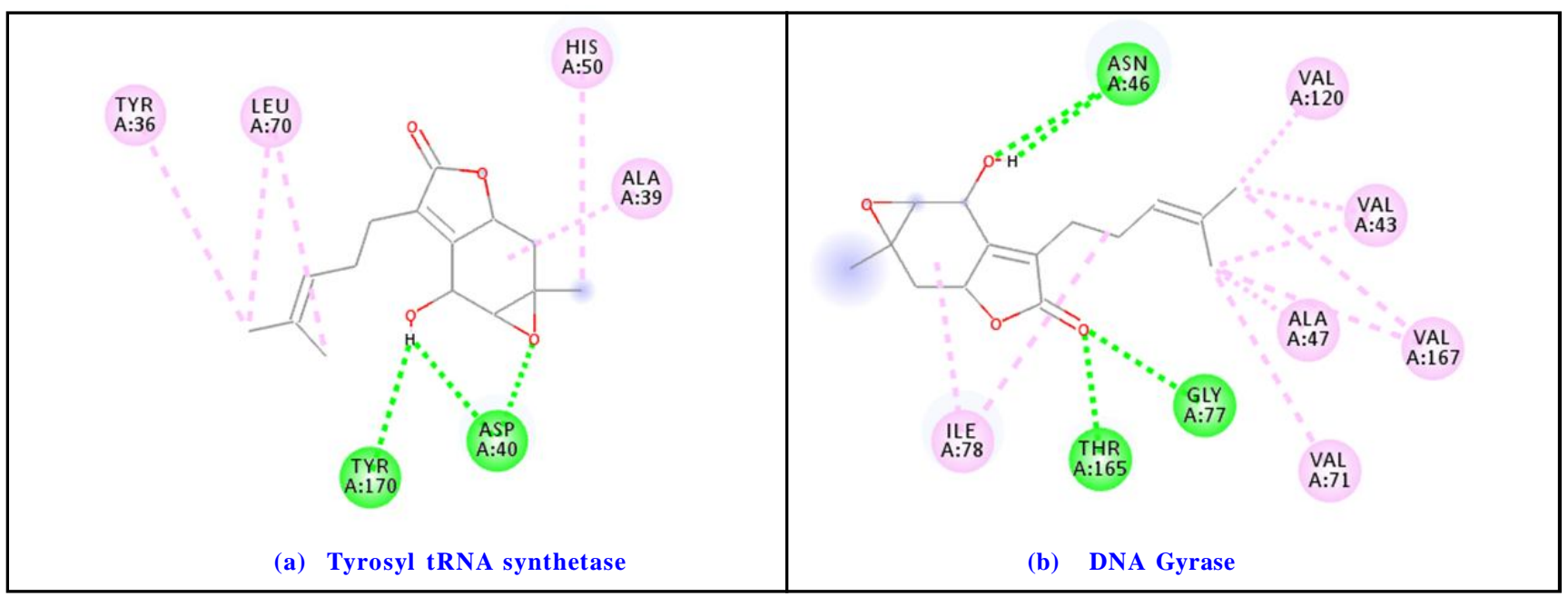

Figure 16: Interaction of paniculide A on target proteins.

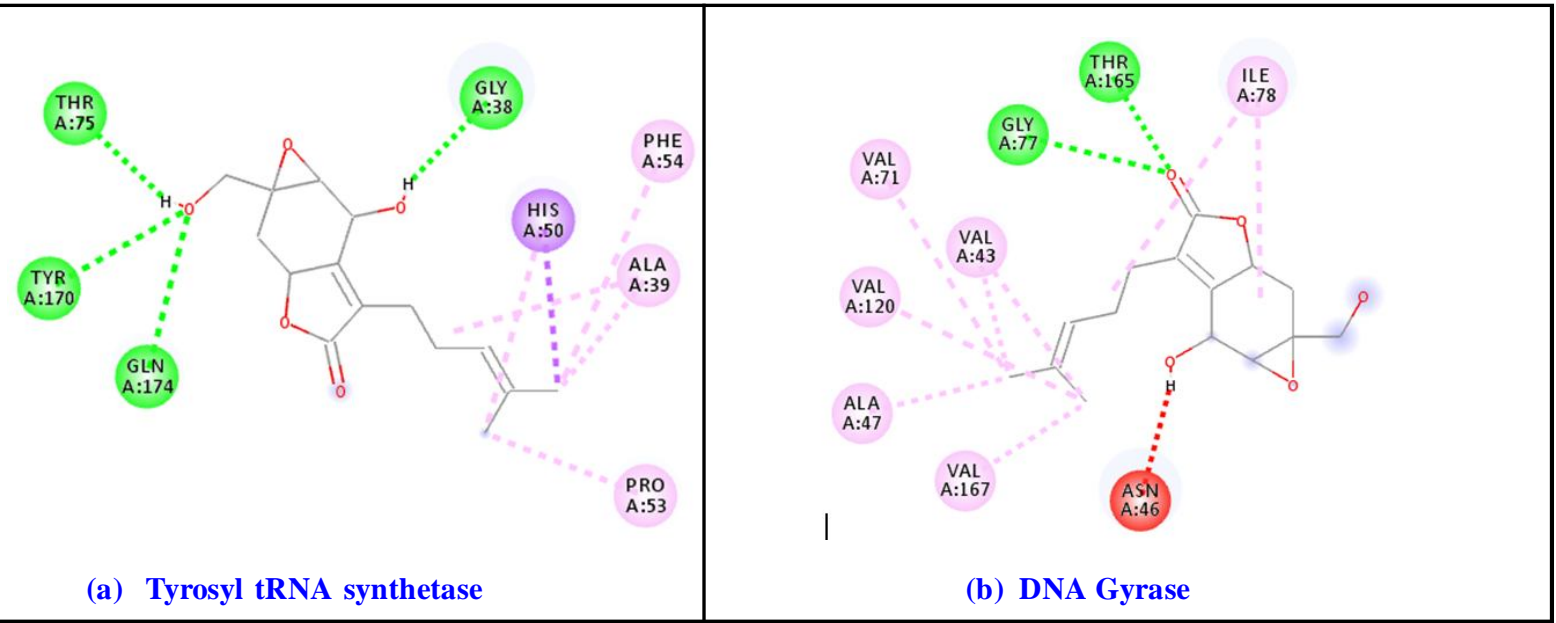

Figure 17: Interaction of paniculide B on target proteins. 


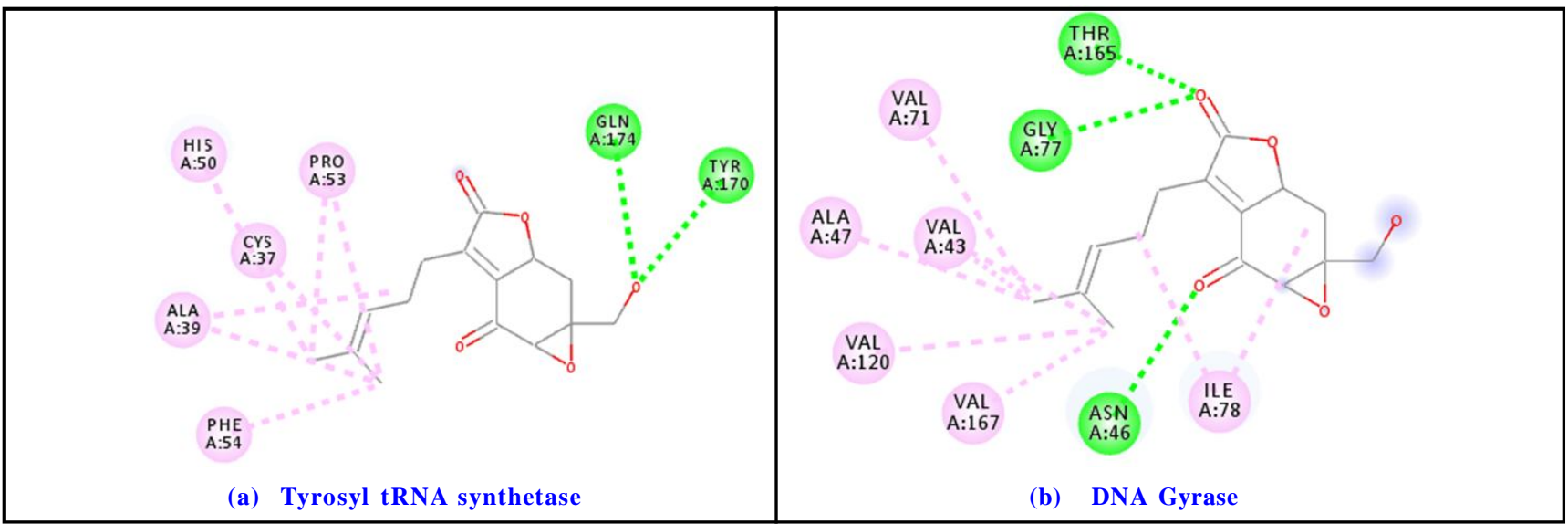

Figure 18: Interaction of paniculide $\mathrm{C}$ on target proteins.

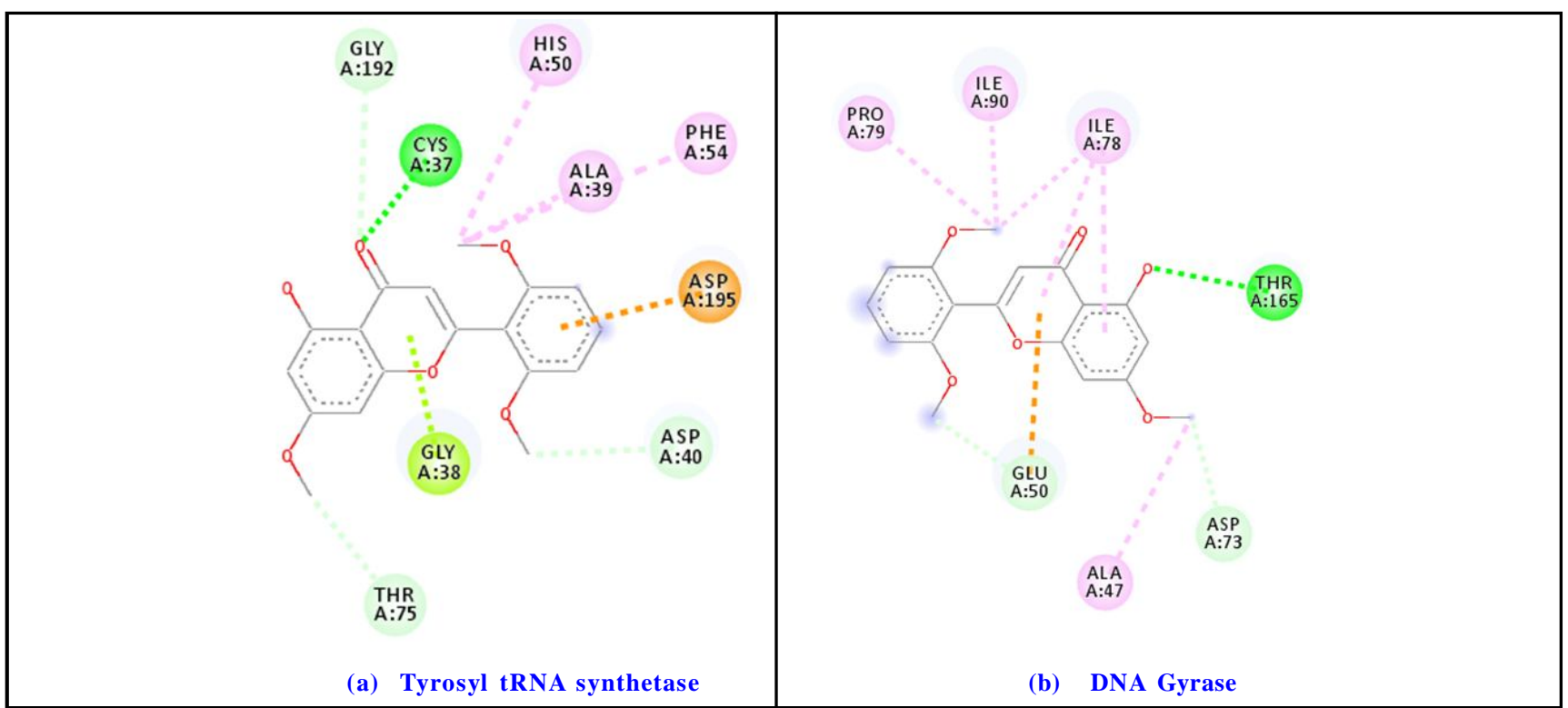

Figure 19: Interaction of 5-hydroxy-7, 2', 6'-trimethoxyflavone on target proteins.



Figure 20: Interaction of Skullcapflavone 1, 2'-O-beta-d-glucopyranoside on target proteins. 


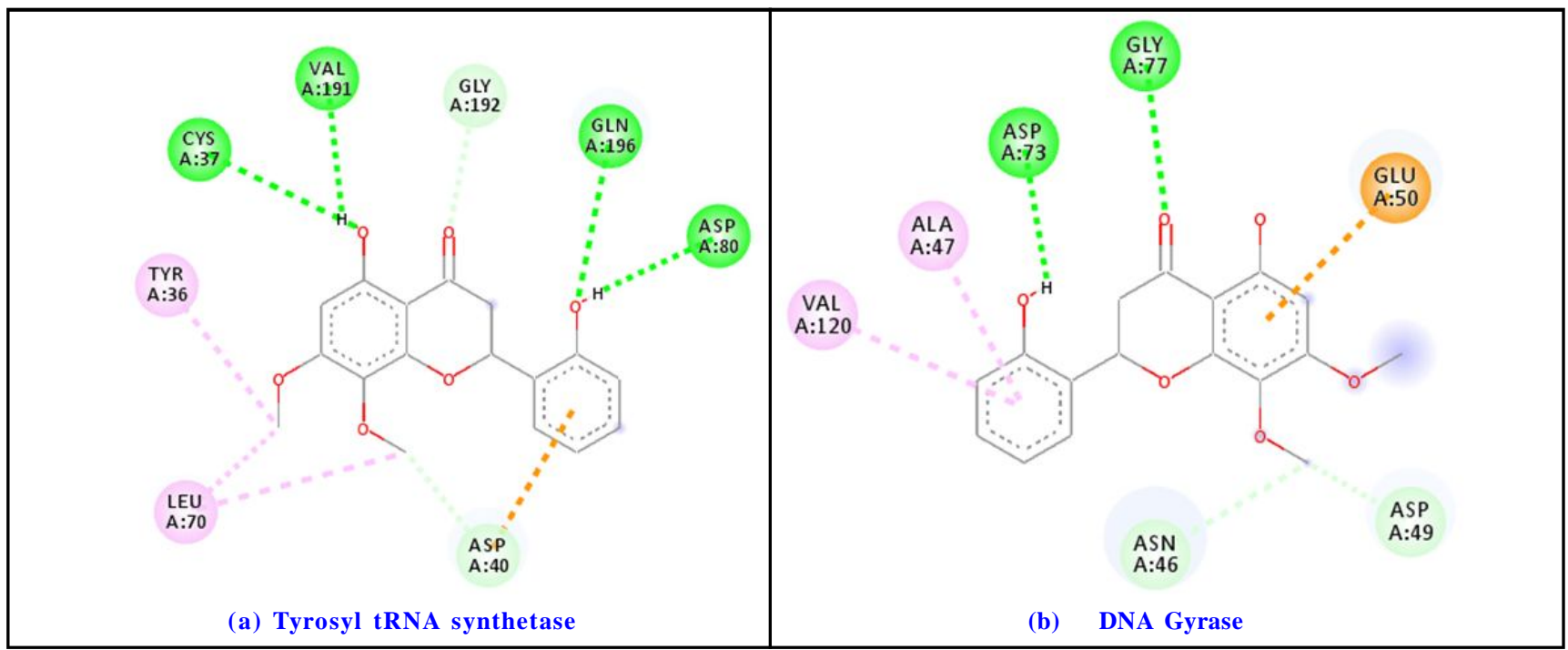

Figure 21: Interaction of dihydroskullcap flavone I on target proteins.

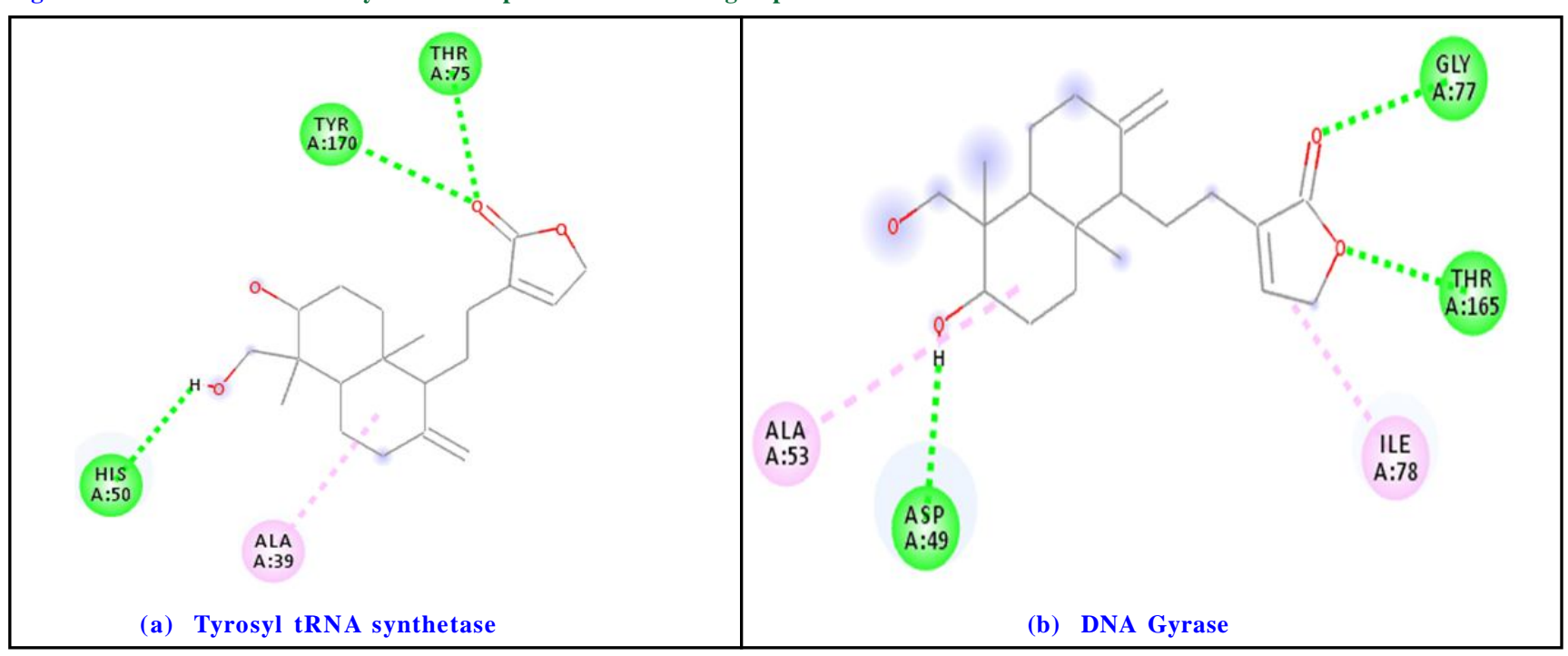

Figure 22: Interaction of 14-deoxyandrographolide on target proteins.

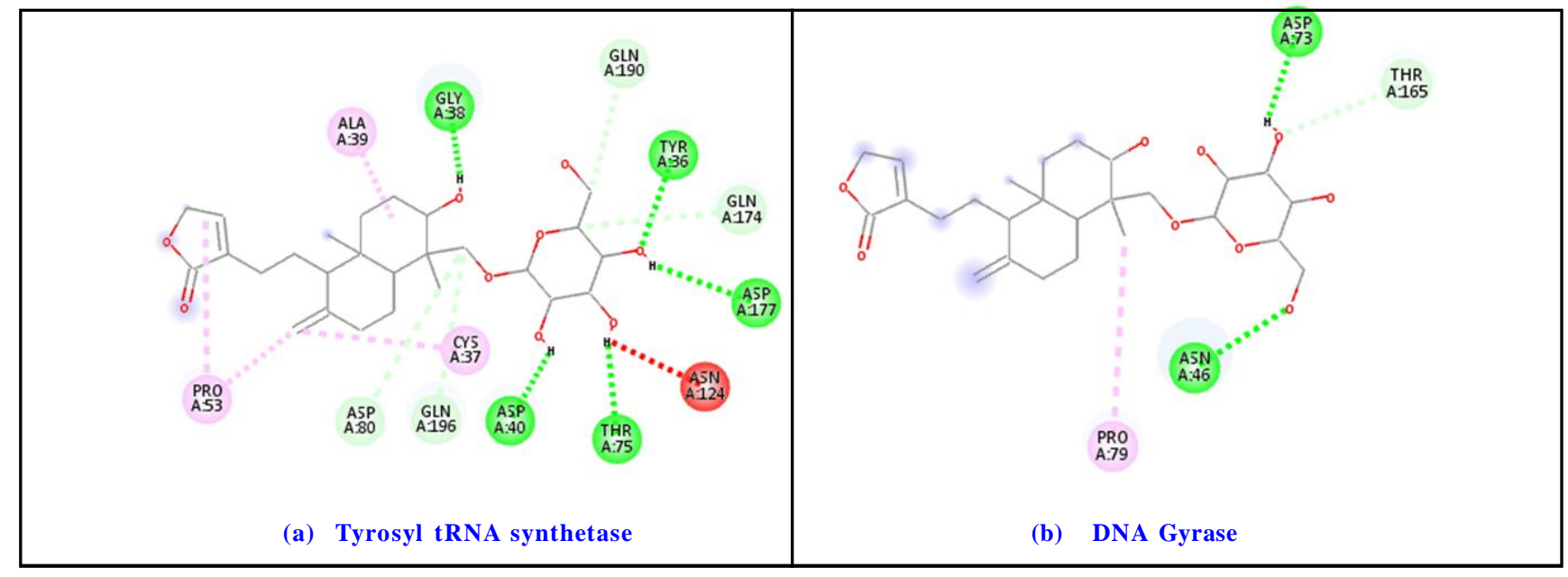

Figure 23: Interaction of ninandrographolide on target proteins. 


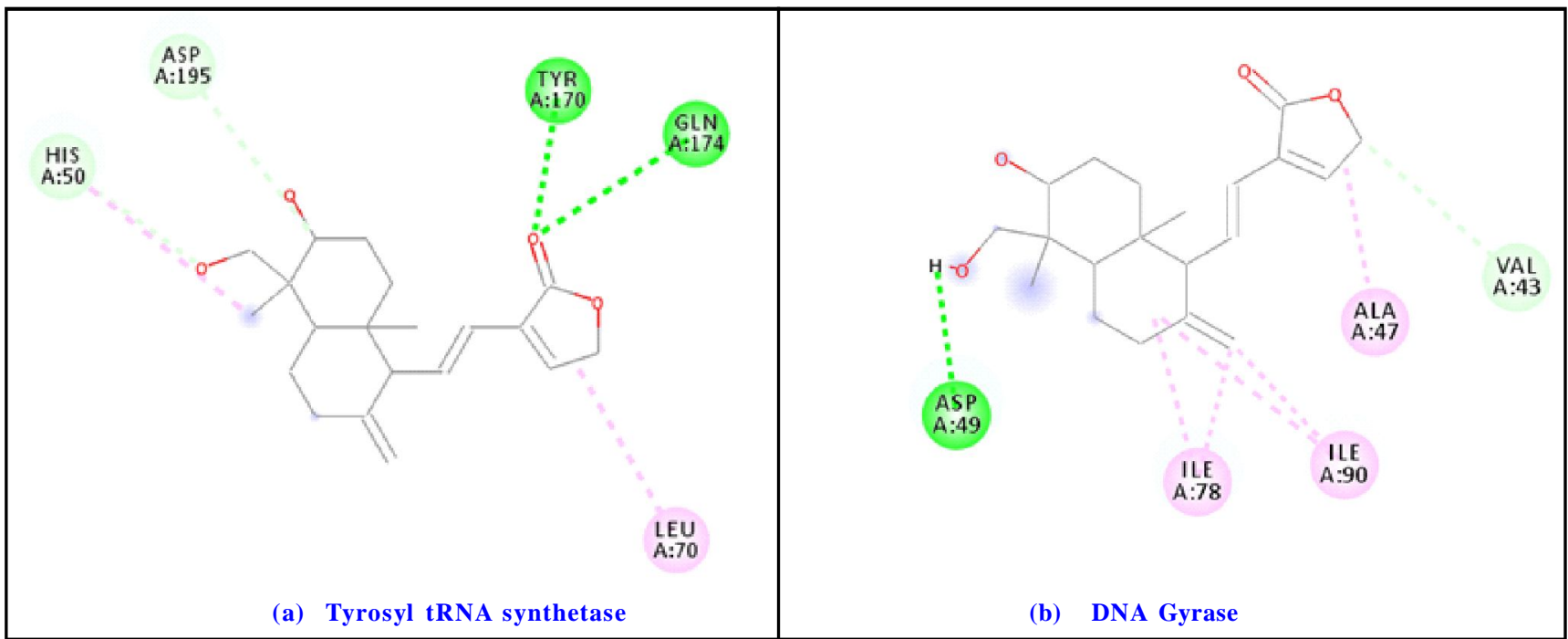

Figure 24: Interaction of 14-deoxy-11,14-didehydroandrographolide on target proteins.

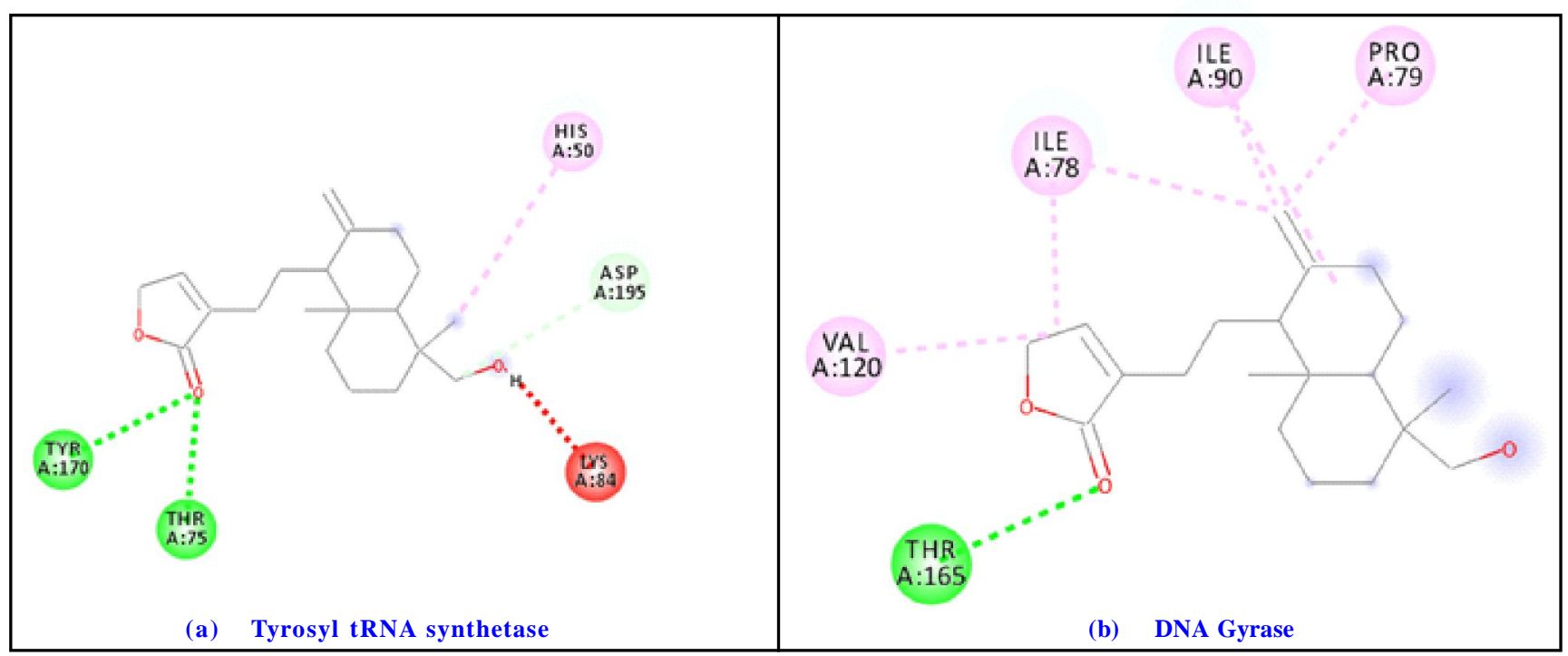

Figure 25: Interaction of andrograpanin on target proteins.

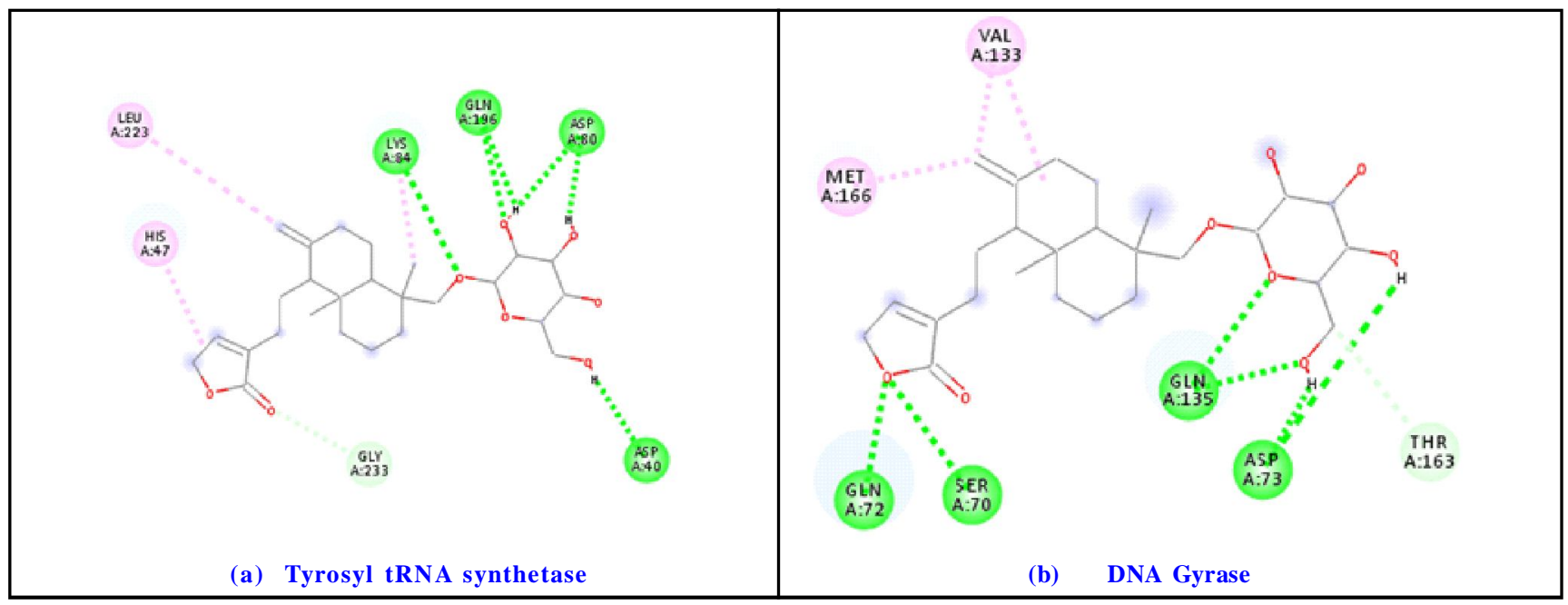

Figure 26: Interaction of neoandrographolide on target proteins. 


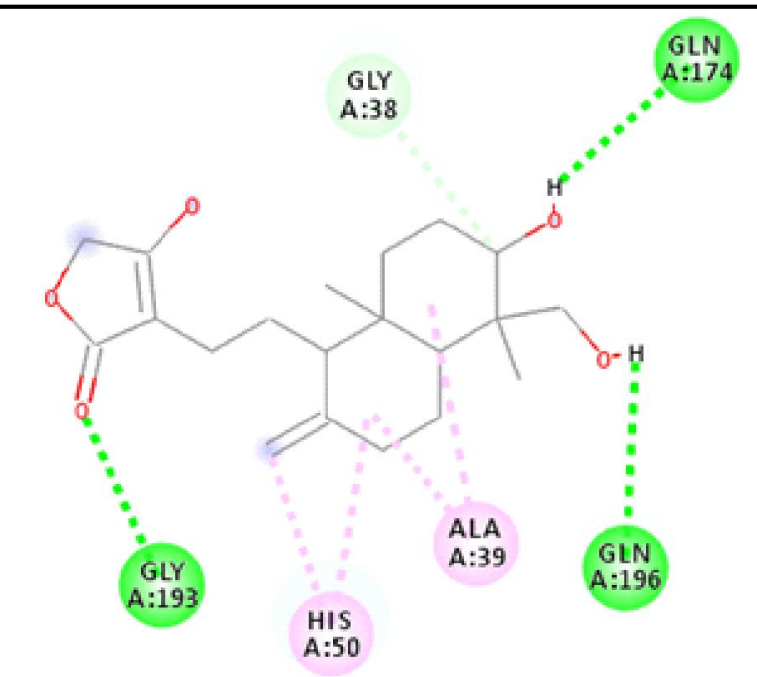

(a) Tyrosyl tRNA synthetase

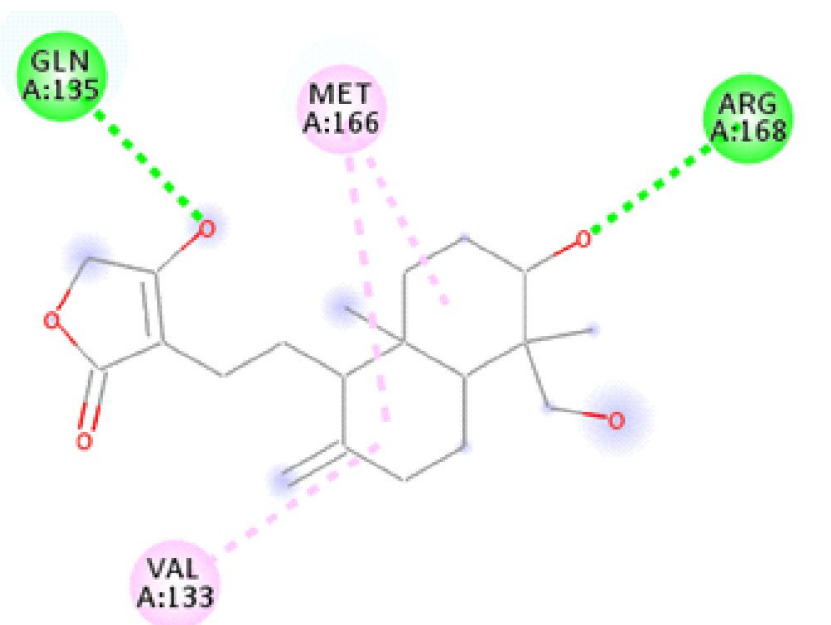

(b) DNA Gyrase

Figure 27: Interaction of andrographolide on target proteins.

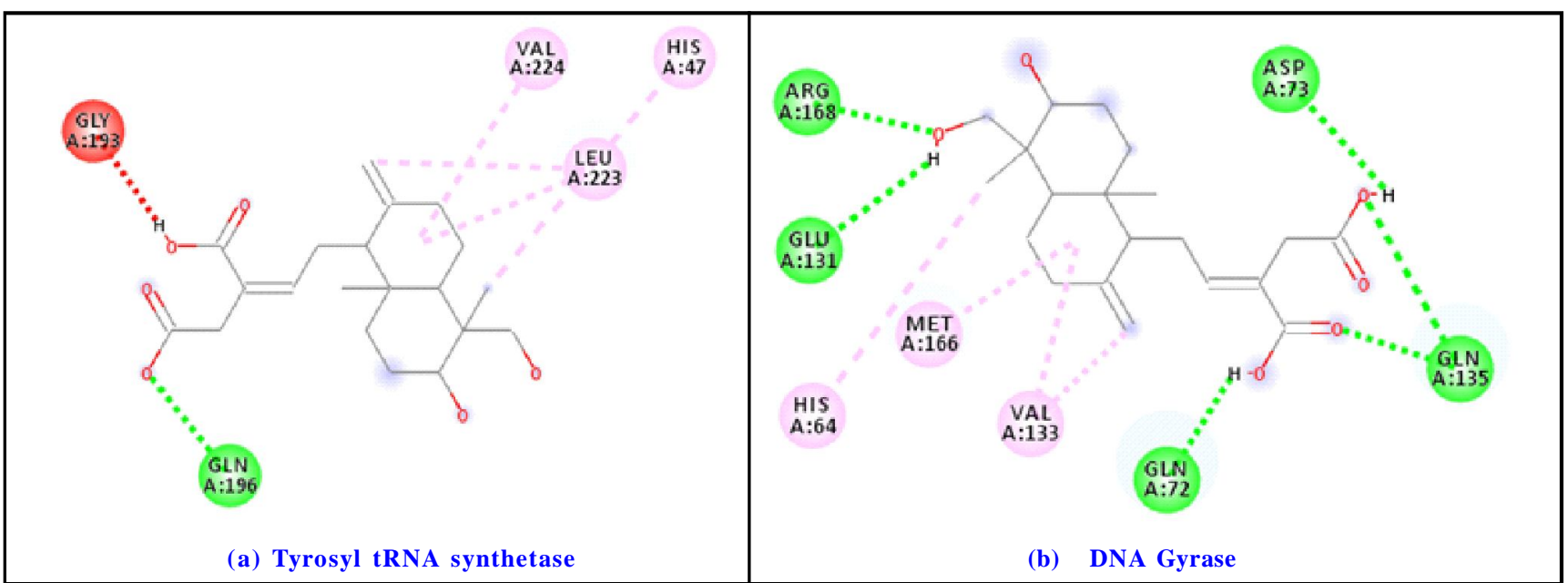

Figure 28: Interaction of andrographic acid on target proteins.

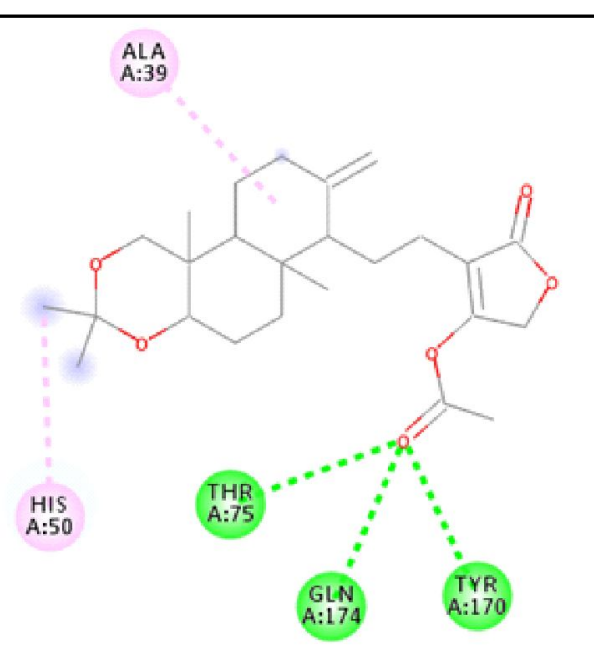

(a) Tyrosyl tRNA synthetase

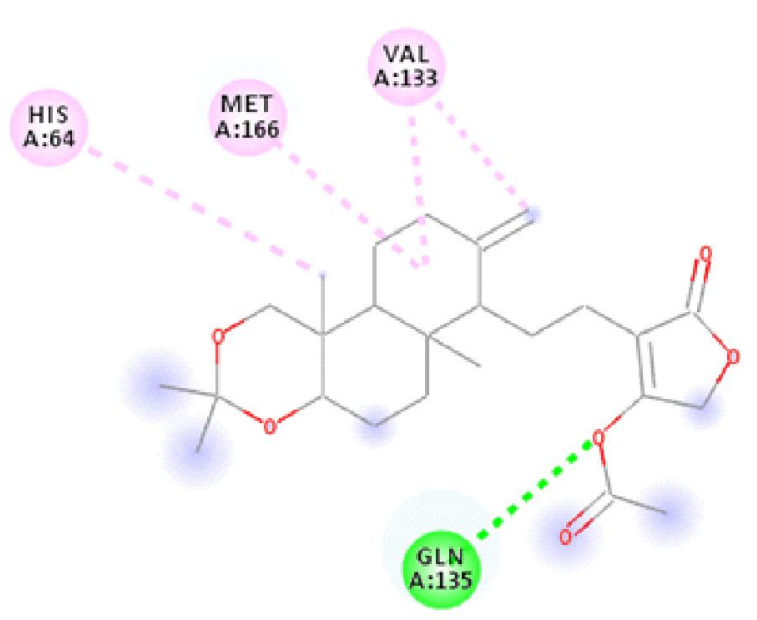

(b) DNA Gyrase

Figure 29: Interaction of 14-acetyl-3,19-isopropylideneandrographolide on target proteins. 


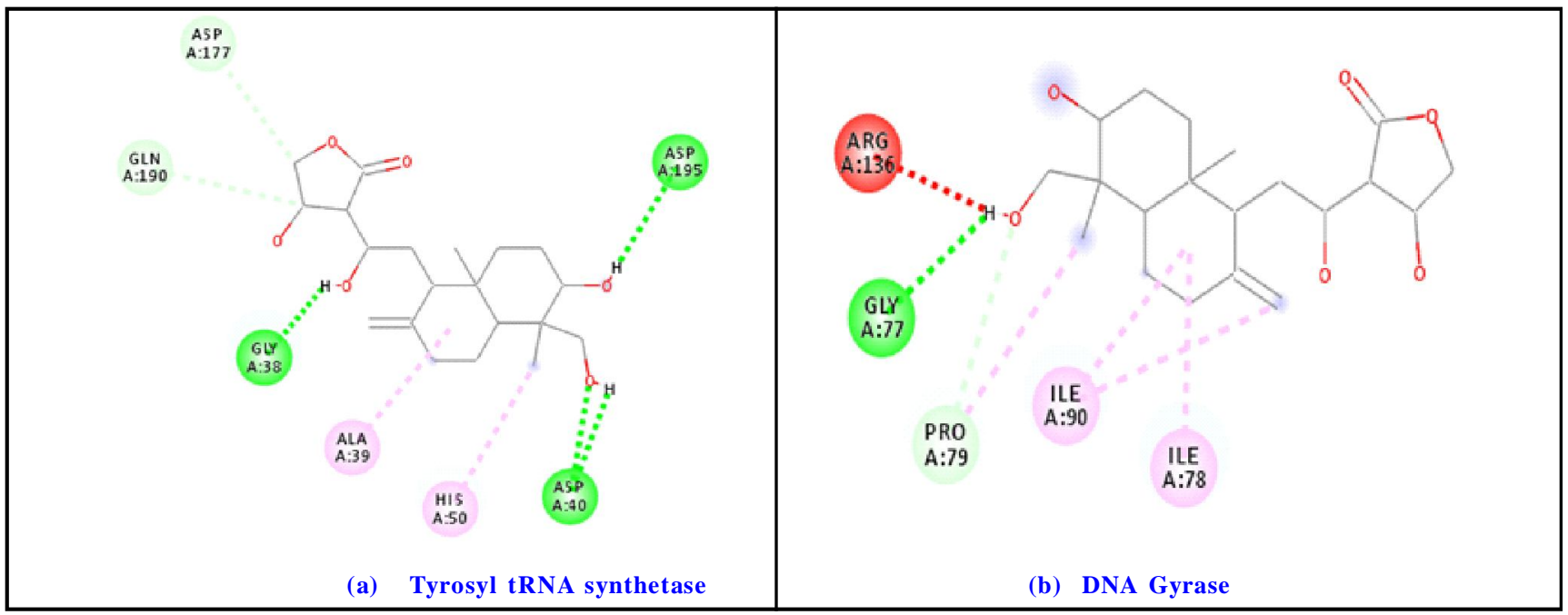

Figure 30: Interaction of 12R,13R-hydroxyandrographolide on target proteins.

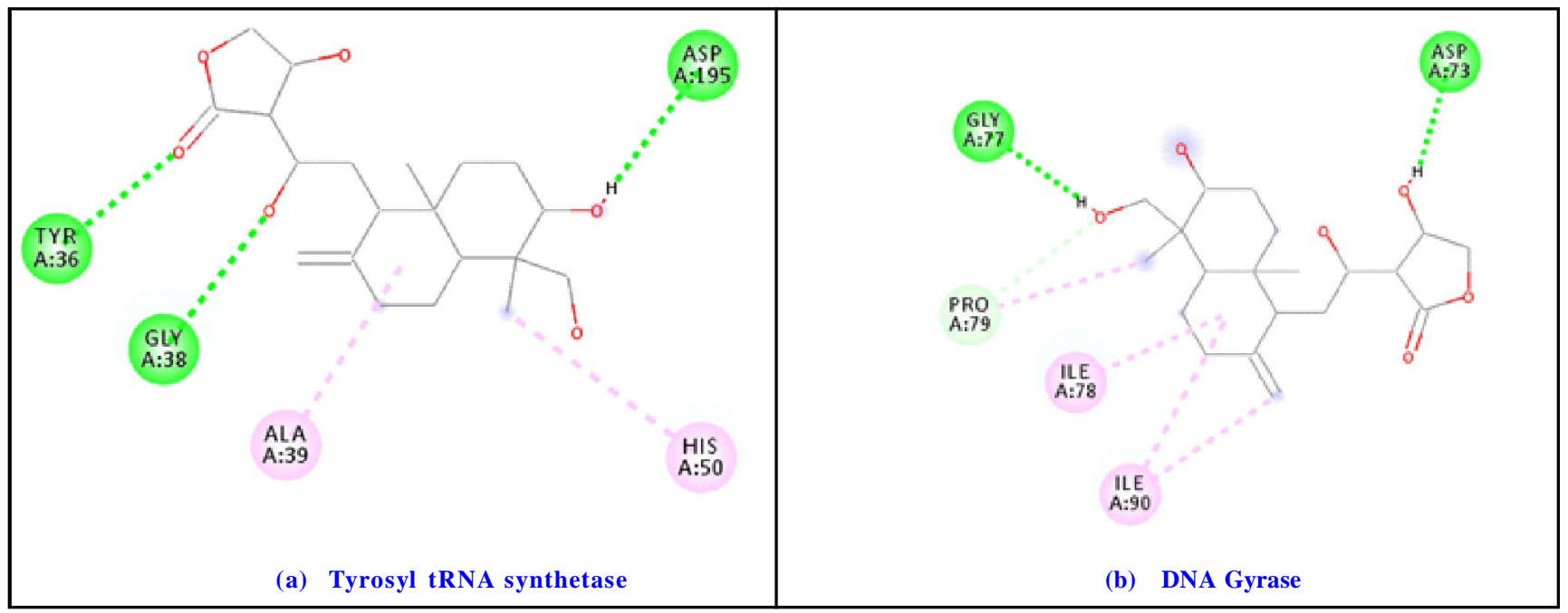

Figure 31: Interaction of 12S,13S-hydroxyandrographolide on target proteins.

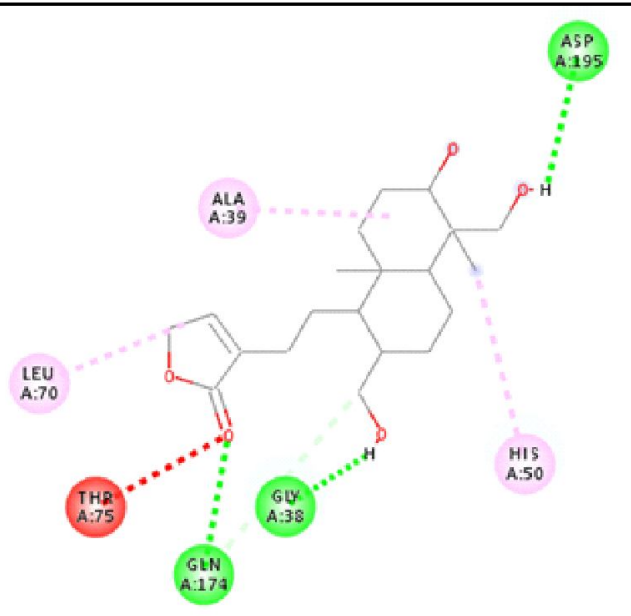

(a) Tyrosyl tRNA synthetase

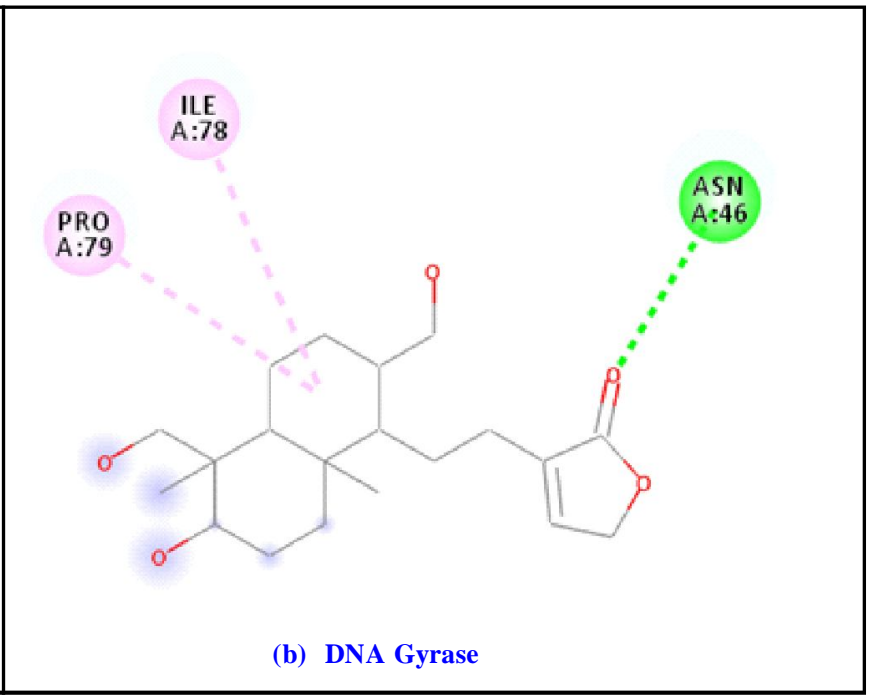

(b) DNA Gyrase

Figure 32: Interaction of 14-deoxy-17-hydroxyandrographolide on target proteins. 


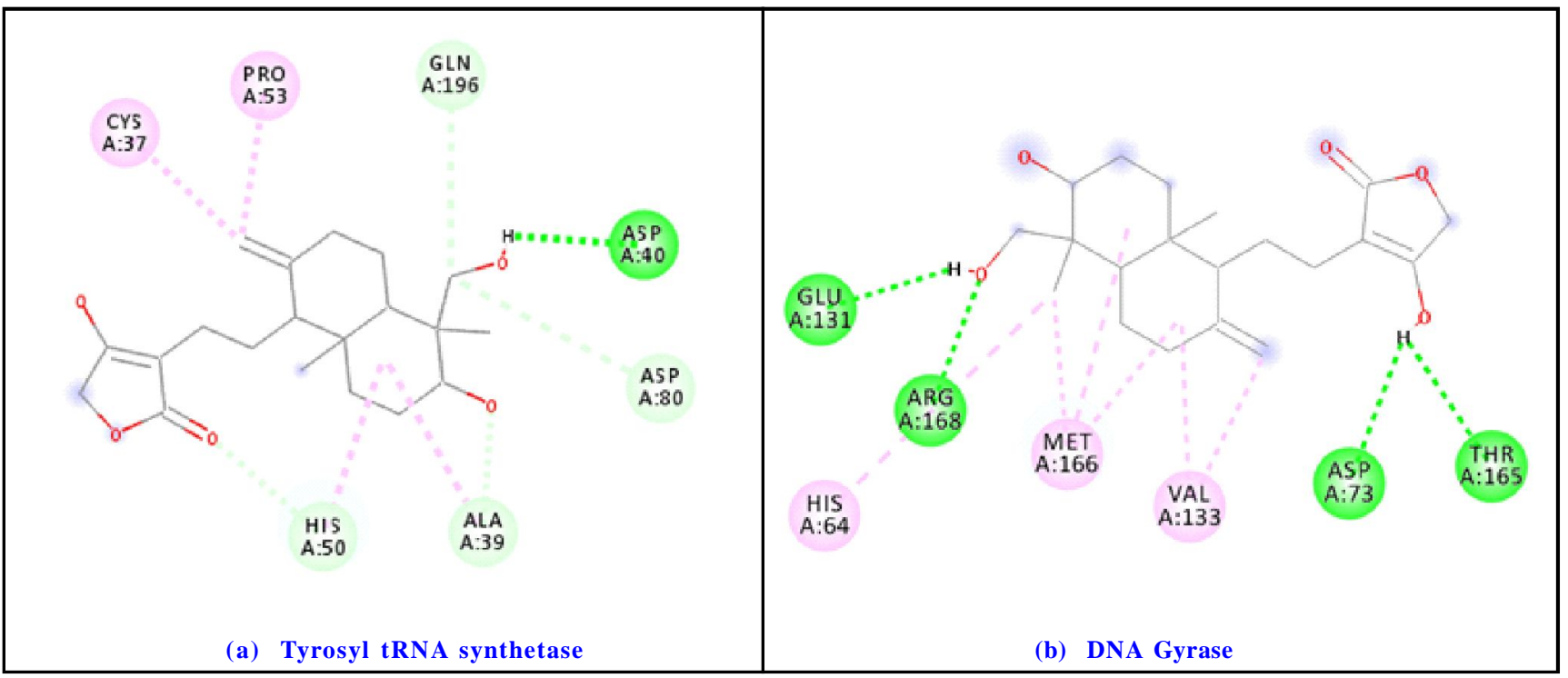

Figure 33: Interaction of andropanolide on target proteins.

\section{Conclusion}

The phytochemical compounds present in T. arjuna and A. paniculata were retrieved from KNApSAck database tyrosyltRNA synthetase and DNA gyrase subunit b were used as target proteins. Preliminarily the compounds were subjected to druglikness analysis. Molecular docking were performed to identify the compounds with higher binding energies $(>-7 \mathrm{kcal} / \mathrm{mol})$ and the compounds were examined for protein-ligand interactions. The selected compounds were examined for in silico ADMET analysis. Nearly, 20 phytochemical compounds were identified with higher binding energies and significant ADMET properties. The compounds were found to be andropanolide, andrographidin A, ninandrographolide, andrograpanin, neoandrographolide, andrographolide, apigenin 7,4'-dimethyl ether, 3-O-caffeoylquinic acid, 7-Omethylwogonin, 5,4'-dihidroxy-7,8,2',3'-tetramethoxyflavone, wogonin 5-glucoside, 5-hydroxy-7,8-dimethoxyflavone 5-glucoside, 5-hydroxy-7,8,2'-trimethoxyflavone 5-glucoside, 5-hydroxy-7,2',6'trimethoxyflavone, Skullcapflavone 1,2'-O-beta-D-glucopyrano side, dihydroskullcap flavone I, 14-Deoxyandro-grapholide, 14Acetyl-3,19-isopropylideneandrographolide, 12S,13S-hydroxy andrographolide. These compounds have potential to be developed as antibacterial drugs for treatment of MDR bacterial infection.

\section{Acknowledgements}

The author is grateful to the Deanship of Scientific Research, Prince Sattam Bin Abdulaziz University, Al-Kharj, Saudi Arabia for its support and encouragement in conducting the research and publishing this report.

\section{Conflict of interest}

The author declares that there are no conflicts of interest relevant to this article.

\section{References}

Abu Bin Nyeem, M.; Abdul Mannan, M.; Nuruzzaman, M.; Kamrujjaman, K. and Kumar Das, S. (2017). Indigenous king of bitter (Andrographis paniculata): A review. J. Med. Plants Stud., 5:318-324.
Amalraj, A. and Gopi, S. (2017). Medicinal properties of Terminalia arjuna (Roxb.) Wight \& Arn.: A review. J. Tradit. Complement. Med., ttps://doi.org/10.1016/j.jtcme.2016.02.003.

Aslam, B.; Wang, W.; Arshad, M.I.; Khurshid, M.; Muzammil, S.; Rasool, M.H.; Nisar, M.A.; Alvi, R.F.; Aslam, M.A.; Qamar, M.U.; Salamat, M.K.F. and Baloch, Z. (2018). Antibiotic resistance: A rundown of a global crisis. Infect. Drug Resist., https://doi.org/10.2147/IDR.S173867

Bintener, T.; Pacheco, M.P. and Sauter, T. (2020). Towards the routine use of in silico screenings for drug discovery using metabolic modelling. Biochem. Soc. Trans., https://doi.org/10.1042/BST20190867.

Borges, A.; Abreu, A.C.; Dias, C.; Saavedra, M.J.; Borges, F. and Simões, M. (2016). New perspectives on the use of phytochemicals as an emergent strategy to control bacterial infections including biofilms. Molecules. https://doi.org/10.3390/molecules 21070877.

C Reygaert, W. (2018). An overview of the antimicrobial resistance mechanisms of bacteria. AIMS Microbiol., https://doi.org/10.3934/ microbiol.2018.3.482.

Cheng, F.; Li, W.; Zhou, Y.; Shen, J.; Wu, Z.; Liu, G.; Lee, P.W. and Tang, Y. (2012). AdmetSAR: A comprehensive source and free tool for assessment of chemical ADMET properties. J. Chem. Inf. Model., https:// doi.org/10.1021/ci300367a.

Collin, F.; Karkare, S. and Maxwell, A. (2011). Exploiting bacterial DNA gyrase as a drug target: Current state and perspectives. Appl. Microbiol. Biotechnol. https://doi.org/10.1007/s00253-011-3557-z

Daina, A.; Michielin, O. and Zoete, V. (2017). SwissADME: A free web tool to evaluate pharmacokinetics, drug-likeness and medicinal chemistry friendliness of small molecules. Sci. Rep., https://doi.org/10.1038/ srep427 17.

Dallakyan, S. and Olson, A.J. (2015). Small-molecule library screening by docking with PyRx. Methods Mol. Biol. https://doi.org/10.1007/ 978-1-4939-2269-7-19.

Elbossaty, W.F. (2017). Antibiotic drugs and multidrug resistance bacteria. Cit. Elbossaty WF Int. J. Pub. Heal. Safe, 2:2-4.

Levy, S.B. and Bonnie, M. (2004). Antibacterial resistance worldwide: Causes, challenges and responses. Nat. Med., https://doi.org/10.1038/ $\mathrm{nm} 1145$ 
Lipinski, C.A.; Lombardo, F.; Dominy, B.W. and Feeney, P.J. (2012) Experimental and computational approaches to estimate solubility and permeability in drug discovery and development settings. Adv. Drug Deliv. Rev. https://doi.org/10.1016/j.addr.2012.09.019.

Nikaido, H. (2009). Multidrug resistance in bacteria. Annu. Rev. Biochem https://doi.org/10.1146/annurev.biochem.78.082907.145923.

Padayachee, B. and Baijnath, H. (2020). An updated comprehensive review of the medicinal, phytochemical and pharmacological properties of Moringa oleifera. South African J. Bot. 129:304-316. https:// doi.org/10.1016/j.sajb.2019.08.021.

Paritala, V.; Chiruvella, K.K.; Thammineni, C.; Ghanta, R.G. and Mohammed, A. (2015). Phytochemicals and antimicrobial potentials of mahogany family. Rev. Bras. Farmacogn. https://doi.org/10.1016/ j.bjp.2014.11.009.

Rédei, G.P. (2008). PubChem, in: Encyclopedia of Genetics, Genomics, Proteomics and Informatics. https://doi.org/10.1007/978-1-40206754-9_13806

Shanthipriya, S.S. and Doss, D.V.A. (2012). Active Site Prediction and Targeting Bipolar Disorder through Molecular Docking Techniques on Protein Kinase Epsilon. Int. J. Sci. Res. https://doi.org/ $10.15373 / 22778179 /$ june2013/11.

Sanjay Prasad, S. and Shanthi, S. (2020). International Journal of Pharma and Bio Sciences Identification of Angiotensin Converting Enzyme (ACE) Inhibiting phytochemical Compounds from Aegle marmelos, Euphorbia hirta, Senna auriculata, Ocimum tenuiflorum and Hibiscus rosasinensis by In Silic 11:79-85. https://doi.org/ 10.22376/ijpbs.2020.11.3.b.

Skupiñska, M.; Stpniak, P.; Ltowska, I.; Rychlewski, L.; Barciszewska, M.; Barciszewski, J. and Giel-Pietraszuk, M. (2017). Natural compounds as inhibitors of Tyrosyl-tRNA synthetase. Microb. Drug Resist. 23, 308-320. https://doi.org/10.1089/mdr.2015.0272.

Tandon, C.; Mathur, P. and Sen, M. (2015). Andrographis paniculata Nees (Kalmegh): A Review on its antibacterial activities and phytocompounds. European J. Med. Plants 8:1-10. https://doi.org/ $10.9734 /$ ejmp/2015/16280.

Tian, W.; Chen, C.; Lei, X.; Zhao, J. and Liang, J.(2018). CASTp 3.0: Computed atlas of surface topography of proteins. Nucleic Acids Res. https:/ /doi.org/10.1093/nar/gky473.

Vidya Devanathadesikan Seshadri (2021). Identification of antibacterial phytochemicals in Terminalia arjuna and 